\title{
Design and Renegotiation of Debt Covenants
}

\author{
Nicolae Gârleanu \\ Jeffrey Zwiebel*
}

This Version: September 2006

\begin{abstract}
We analyze the design and renegotiation of covenants in debt contracts as a specific example of the contractual assignment of property rights under asymmetric information. In particular, we consider a setting where managers are better informed than the lenders regarding potential transfers from debt to equity that are associated with future investments. We show that this simple adverse-selection problem leads to the allocation of greater ex-ante decision rights to the creditor (the uninformed party) - i.e., tighter covenants - than would follow under symmetric information. This corresponds well with empirical evidence indicating covenants are indeed very tight upon inception. Strict covenants in turn lead to a bias in ex-post renegotiation, with the creditor giving up these excessive rights - i.e., covenants are waived. This result contrasts with the conclusion of standard incomplete contracting models of ex-ante hold-up, where the party with the more important ex-ante investments - presumably management, rather than the creditors - is granted decision rights.
\end{abstract}

\footnotetext{
*Gârleanu: Wharton School, University of Pennsylvania, 3620 Locust Walk, Philadelphia, PA 19104-6367, email garleanu@wharton.upenn.edu; Zwiebel: Graduate School of Business, Stanford University, Stanford CA 94305, email zwiebel@stanford.edu. We are grateful to George Baker, Bernard Black, Patrick Bolton, Philip Bond, Peter DeMarzo, Itay Goldstein, Hayne Leland, Jonathan Levin, Michael Roberts, Neil Stoughton, Steve Tadelis, Ralph Winter, several anonymous referees, and seminar participants at Carnegie Mellon, Columbia University, DePaul University, Duke University, New York University, Stanford University, the University of British Columbia, UCSD, the University of Utah, USC, the American Finance Association Meetings, the NBER Conference on Organizations, the European Finance Association Meetings and the Western Finance Association Meetings, for helpful comments.
} 
In this paper we analyze the design and renegotiation of covenants in debt contracts as a particular example of the contractual assignment of property rights under asymmetric information. We start with the presumption that debtholders are less informed than an entrepreneur about potential future transfers from debt to equity, and explore the implications of this adverse selection on the design and subsequent renegotiation of debt covenants. Intuitively, we analyze the notion that debtholders may receive stronger decision rights (in the form of tighter debt covenants) than under symmetric information, in order to "protect" them from an informational asymmetry, and the implications this will in turn have for information acquisition and future covenant renegotiation.

Covenants are a common feature of debt contracts, and are generally understood to protect debtholders against activities that transfer wealth from them to shareholders. Most corporate debt contracts include covenants that place restrictions on the issuing firm, and thereby effectively serve to allocate control rights, in certain states of the world. For example, a firm might not be allowed to issue new debt if net working capital is below a specified level or if an interest coverage ratio is too low. Common covenant conditions are based on firm net worth, working capital, leverage, interest coverage, and cash flow; and involve restrictions on issuing debt, paying dividends, and investing, or impose actions such as the acceleration of debt payments if the specified condition is binding. ${ }^{1}$

A striking empirical regularity, however, is less well understood: covenants are remarkably tight. Chava and Roberts (2005) documents that at the inception of a debt contract, the average covenant threshold is only about one standard deviation away from the current value of the accounting ratio in question. As a consequence, 15\%-20\% (depending on the type of covenant) of outstanding loans are in violation during a typical quarter, and conditional on violating a covenant, a loan is delinquent about $40 \%$ of the time. Overall, for current-ratio covenants, about $50 \%$ of firms and $42 \%$ of loans are delinquent at some point in their lives, while for the less frequently violated net-worth covenant, about $30 \%$ of the loans are delinquent at some time. Furthermore, given such tight initial covenants, loans often fall into violation very quickly. The median covenant violation occurs at the end of the first third of the life of the loan, which translates to only one year from the inception of the loan. One direct implication of this tightness is that covenants are frequently renegotiated, and when they are the conditions imposed on the firm are routinely relaxed (or waived), and virtually never strengthened. ${ }^{2}$ Our analysis yields a simple explanation based on asymmetric information

\footnotetext{
${ }^{1}$ See, for example, Smith and Warner (1979), Smith (1993), and Bradley and Roberts (2004).

${ }^{2}$ In a typical covenant waiver, the debtholder allows the manager to undertake some action prohibited in an initial covenant or relaxes the covenant that is in breach, in exchange for a higher interest rate and/or new additional restrictions. Note that in principle, covenants that are not in violation could also be renegotiated to be strengthened, by prohibiting some previously allowed actions or by tightening the triggering threshold in exchange for a lower interest rate. The asymmetry we note in the text is that while the first type of renegotiation (relaxing the covenant) is common, the latter type of renegotiation (strengthening the covenant) is virtually unseen in practice. See, for
} 
and costly renegotiation for the observed tightness of covenants and subsequent debt-contract renegotiation.

Insofar as covenant "tightness" has not received much direct attention in the literature, we elaborate here on the observation that covenants are surprisingly strict. Covenant tightness can be understood as a decision regarding the allocation of decision rights, as covenant violations typically grant debtholders the right to intervene in decisions that they otherwise would not have the right to intervene in absent the violation. To address how strict one should expect covenants to be, one must first consider the role covenants play, and the reason they are frequently renegotiated.

Covenants serve to protect lenders from activities that prevent transfers to borrowers. Efficiency considerations, however, dictate that some activities that transfer wealth from debtholders to shareholders should be permitted, and some should be restricted. For example, the investment in both good (positive NPV) and bad (negative NPV) new projects are likely to involve a transfer from pre-existing debtholders to shareholders, by increasing the risk in firm returns. ${ }^{3}$ It is of course in the interest of the entrepreneur, as well as the lender, to design a contract that will induce efficient ex-post investment decisions, insofar as any anticipated transfers will be reflected in the issue price of the debt. In practice, however, it is typically not feasible to contractually delineate all future positive NPV projects ex-ante, or for a court to ex-post enforce such a vague contractual provision. Consequently, covenants are instead conditioned on more easily observable accounting variables, such as financial ratios, that are likely to be imperfectly correlated with the availability of good future projects, and are then renegotiated when more information becomes available.

If this ex-post renegotiation was costless and efficient, and if information was symmetric, the Coase theorem indicates that the strictness of the initial covenants would not matter: renegotiation would ensure that the efficient decision would always be made ex-post, and the accompanying transfers necessary to allow this would be offset in the original contract through level of the interest rate (Coase (1960)). If instead renegotiating was costly, but information was still symmetric, one would expect to see contracts written to minimize the need for renegotiation by anticipating, as efficiently as possible, future optimal investment decisions. That is, covenants would not be written in a manner that induced frequent future violations that were waived upon renegotiation: i.e., covenants would be less strict than what is observed. And if we added to this setting the potential hold-up of ex-ante investments (that is, the friction most commonly presumed in the incomplete

example, Beneish and Press (1993), Sweeney (1994), and Beneish and Press (1995). Technically, Beneish and Press (1993) do find some covenants that are tightened during renegotiation. However, as noted by Smith (1993), this is likely to involve replacing binding covenants with tighter nonbinding covenants on other variables.

${ }^{3}$ We will take such "asset substitution activity" of Jensen and Meckling (1976) as a canonical case, but any other activity that transfers wealths from debtholders to shareholders would serve the same purpose in our model. There is a voluminous finance literature that focuses on the size, costs, and consequences of asset substitution and on other manners of wealth transfer. 
contracting literature), one would expect covenants to be weaker still. This follows from noting that decision rights should be allocated in order to minimize distortions in ex-ante investments due to the potential of future hold-up; ${ }^{4}$ and ex-ante "effort" by entrepreneurs or managers is likely to be more important to the success of investment projects than similar "effort" by outside debtholders (who frequently play a passive role in firm investments). Consequently, it appears rather surprising that in practice covenants are so strict and consequently so often in violation.

The explanation that our model provides to this observed strictness is neither deep nor complicated. It does, however, highlight what we believe to be an important consideration in the assignment of decisions rights, both for debt contracts and in other more general settings, that has generally received little attention to date. In particular, in our setting, lenders receive strong decision rights as a consequence of asymmetric information. Simply put, if debtholders are less informed than an entrepreneur about the potential for future transfers, strong decision rights (through covenants that effectively allow the vetoing of new investments) may "protect" them from such transfers. Complicating matters, however, is the fact that lenders with strong rights may also prefer to veto efficient projects as well as inefficient ones, necessitating renegotiation. Our model is designed to analyze how robust this general notion is in an equilibrium setting where decision rights in contracts affect inferences and consequently prices (interest rates), and ex-post renegotiation is possible. While the model in the text is stylized to keep the analysis simple, we also demonstrate in Appendix A that our results carry through to a far more general setting which maintains a few basic elements of our model.

These necessary elements are straightforward: First, there is incomplete information ex-ante about a future decision. In our setting, an entrepreneur needs to raise money from a lender to undertake a project at time 0 . At a future date (time 1), a decision must be made whether to invest further and expand the project. The efficiency of this time- 1 decision depends on the time- 1 state of the world, which is not known by either party ex-ante (at time-0), but which is known by both parties prior to the investment. While the time- 1 state of the world is non-contractible at time- 0 , the initial contract can allocate the right to make the time- 1 decision. Second, there is an agency conflict. For simplicity we assume that it is always beneficial for entrepreneurs to invest further at time 1 , and it is always detrimental for the lender. Third, there is asymmetric information regarding the division of surplus under the new investment. In our model, the new investment will transfer an uncertain quantity $x$ from the lender to the entrepreneur, where the entrepreneur knows the realization of $x$, but the lender only learns this realization at a cost. And fourth, prior to the time-1 investment, the two parties can renegotiate the decision to be made, or,

\footnotetext{
${ }^{4}$ See, for example, Klein, Crawford, and Alchian (1978), Grout (1984), Williamson (1985), and Grossman and Hart (1986) for the starting point of this very large literature.
} 
equivalently, who gets to make this decision.

In this setting, we find that stronger rights (tighter covenants) are granted to the lender in the initial contract the greater the asymmetric information, the more costly it is for the lender to become informed, and the less costly it is to renegotiate. Intuitively, lacking information about future asset substitution, the lender must form inferences about the entrepreneur's information based on the contract that is being offered. In equilibrium, the entrepreneur will have to compensate the lender for the inferred amount of asset substitution activity that will ensue. "Good types" - i.e., entrepreneurs who do not have as much such activity at their disposal - will prefer to give strong decision rights to lenders, even though this leads to excessive renegotiation and expost information-acquisition costs, due to the adverse selection problem. Consequently, lenders on average will be given stronger decision rights than would follow under symmetric information. Ex-post renegotiation will in turn be biased towards the uninformed party giving up these excessive rights, thereby yielding asymmetric renegotiation. ${ }^{5}$

Our setup also allows us to analyze a natural trade-off between early and late acquisition of information. The early acquisition of information will allow the lender to negotiate the initial contract without an informational disadvantage, which may lead to a more efficient contract. However, for some states of the world, acquiring this costly information will prove to be unnecessary; if a state is reached at time 1 where there is no scope for renegotiation, there is no need for the lender to be informed. Our lenders must trade off this cost and this benefit when choosing whether to acquire information ex-ante or ex-post. ${ }^{6}$

Our paper follows the program laid out in the Grossman-Hart-Moore Property Rights literature in analyzing the optimal assignment of decision rights given contractual incompleteness. ${ }^{7}$ However, we depart from most of this large literature by considering the contractual implications of asymmetric information with costly information acquisition rather than the standard inefficiency of the hold-up of non-contractible ex-ante actions. ${ }^{8}$

\footnotetext{
${ }^{5}$ Bradley and Roberts (2004) finds that loans are more likely to include covenants when the borrower is small, has high growth opportunities, or is highly levered. These results are readily interpretable in our setting to the extent that asymmetric information about future transfers is greater with such firms. We would argue that all three are likely: For example, the scope for asset substitution activities or cash diversions is likely to be larger for firms with fewer reporting standards and for growing firms with more investment opportunities. See Malitz (1986) for similar results. We discuss empirical implications of our model more in Section 4.

${ }^{6}$ Designing an optimal contract to avoid information costs (i.e. verification costs) in as many states as possible is of course central to the costly state verification framework of Townsend (1979) and Gale and Hellwig (1985). Our setup differs in that our lender is presumed to be at an ex-ante informational disadvantage and might choose to mitigate this by learning (ex-ante) about future states of the world. Under costly state verification, both parties are equally informed ex-ante, and the contract is designed to try to allow the lender to avoid ex-post verification costs.

${ }^{7}$ See Grossman and Hart (1986), Hart and Moore (1990), and Hart (1995).

${ }^{8}$ Stole and Zwiebel (2005) has argued that while ex-ante non-contractible investments have received an enormous amount of attention in the literature, there are other likely manners of contractual incompleteness, yielding new implications for the allocation of decision rights and ownership that have been relatively unexplored, which merit further attention.
} 
One notable incomplete contracting paper that does consider the effect of asymmetric information in the design of debt covenants is Sridhar and Magee (1997). This paper, however, focuses on very different aspects affecting the assignment of covenant rights from us; notably, the informativeness of contractible variables and the scope for accounting misrepresentations. Furthermore, their model assumes the asymmetry in renegotiations that we derive as a central result in our analysis; i.e., they assume that only the lender, and not the owner, can relinquish rights (through unilateral covenant waivers when it is beneficial for them to do so). ${ }^{9}$

Also related is the financial contracting literature that considers the use of financial contracts to assign control rights across different states of the world. See for example, Zender (1991), Aghion and Bolton (1992), Dewatripont and Tirole (1994), Berglöf and Von Thadden (1994). In our setting, however, financial contracts cannot distinguish between states of the world, and, rather, renegotiation serves to allocate control rights across states ex-post. Most closely related in this literature is a recent paper by Dessein which considers the assignment of control rights under asymmetric information, applied to a contract between an entrepreneur and a venture capitalist. While Dessein (2005) differs from ours in a number of significant manners: private benefits lead to noncontractible agency conflicts rather than the future transfers, informational and contracting assumptions differ, renegotiation is not considered; it also finds that the informed party (the Entrepreneur) gives up control rights to the uninformed party (the Venture Capitalist) in order to signal congruent preferences. $^{10}$

Finally, there is an empirical finance literature speaking to other aspects of debt covenants. For example, a number of papers consider the price impact of debt covenants; see, for example, Bradley and Roberts (2004) or Harvey, Lins, and Roper (2004) for some recent results.

While we focus on the interpretation of debt covenants in this paper, our model could be applied equally well to a number of other contracting settings where asymmetric information regarding transfers is important. In the conclusion we briefly comment on applications of our model to home-mortgage contracts, procurement contracts, sports labor contracts and biotechnology joint ventures.

\footnotetext{
${ }^{9}$ Also notable are Spier (1992) and Hermalin (1988), which demonstrate that contractual incompleteness may arise from adverse selection. This bears some similarity to our setting where the choice by the informed party of decision rights signals information about transfers associated with future decisions. However, by assumption, the decision rights are always contracted on in our setting (i.e., the contract is not incomplete in this dimension). As such, our focus is on the effect of asymmetric information on the allocation of such rights and on subsequent information acquisition, rather than on contractual incompleteness. Huberman and Kahn (1988) notes that costly contractual contingencies should decrease with the ability to renegotiate contracts.

${ }^{10}$ In related papers, Kirilenko (2001) shows that an entrepreneur might relinquish control in order to maintain price noisiness that supports equilibrium trade, while Harris and Raviv (2005) study control allocation within a firm in a setting in which both the CEO and a manager have relevant information that they can convey partially via cheap talk.
} 
The paper is organized as follows. Section 1 presents our model, Section 2 characterizes its equilibrium, and Section 3 analyzes properties of this equilibrium and gives intuition. Section 4 highlights some empirical implications, and Section 5 concludes. Further extensions that more explicitly model several features specific to debt contracts, and proofs, are given in the appendices.

\section{The Model}

We consider a wealth-constrained entrepreneur $E$ who needs funding $I$ at time 0 to undertake a project. Ex-ante $E$ faces a competitive lending market and consequently offers a break-even contract to a lender $L$ in return for $I$. Both $E$ and $L$ are risk-neutral, and for simplicity, the discount rate is 0 . If undertaken, this project yields a certain return of $R$ at time 2 (provided that no further investments - described below - are taken). In return for this financing, $E$ signs a contract $\{r, D\}$ specifying a promised (deterministic) payment $D$ to $L$ when returns are realized, and an allocation of the time-1 decision right to one party $r \in\{E, L\}$ (as described below). Note that we concentrate exclusively on debt contracts and study the optimal allocation of control within this class of contracts. We do not address the more general security-design question, assuming instead that debt is chosen for common reasons that we do not model. ${ }^{11}$

If the parties enter into such an agreement, play proceeds as summarized in the timeline of Figure 1, which we now describe in detail. Conditional on undertaking the project at time 0 , there is an opportunity to undertake a further investment at time 1 . One interpretation is simply an expansion of the initial project. This further investment requires no additional cash outlay. We denote the decision to take or not take this additional investment by $A$ (action) and $N A$ (no action), respectively. The initial time- 0 contract specifies who has the right to make this investment decision; if this right is assigned to $L$, we will call this a covenant. ${ }^{12}$ However, the parties may choose to renegotiate prior to this investment decision. In particular, the party that does not have the decision

\footnotetext{
${ }^{11}$ For our purpose, all we need is a contract that introduces an agency conflict between the creditor and the firm regarding transfers under future actions. Similar implications would follow with alternative contracts with this feature. Also, while we speak of an entrepreneur holding equity, we could equivalently speak of a manager acting on behalf of shareholders.

${ }^{12}$ In practice, debt covenants that allow debtholders the right to veto investments are generally contingent on a verifiable state of the world; e.g., a low capital ratio. Such contingent covenants would naturally follow in our model, to the extent that new investments primarily transfer wealth from lenders to shareholders only in certain verifiable states (i.e., when the firm is in or near financial distress). Such contingencies could easily be accounted for, albeit at the cost of needlessly complicating the model. In particular, consider the following addition to the model: Assume that there is an additional moment in time - say, time $\frac{1}{2}$ - between when the initial contract is signed at time 0 and time 1. Between time 0 and time $\frac{1}{2}, L$ and $E$ learn whether $E$ is in "financial distress" or not, an event presumed to be contractible at time 0 . If $E$ is not in financial distress, then no asset substitution activities are possible (as debt will be safe and paid for sure). If $E$ is in financial distress, the game proceeds as in our model, with the same payoffs. In such a setting, the equilibrium time- 0 contract would grant the entrepreneur control contingent on there being no financial distress at time $\frac{1}{2}$, and would follow our equilibrium contingent on financial distress.
} 


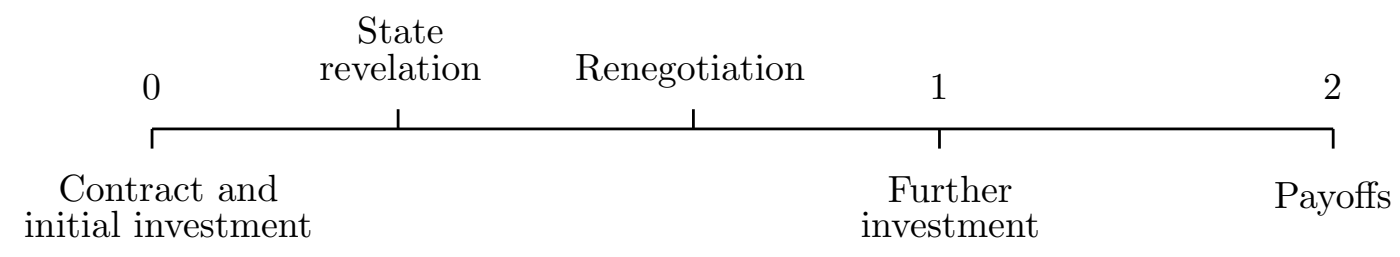

Figure 1: Time diagram

right might pay the other party in order to take a different action (or, equivalently, to transfer the decision right). We let $t$ represent the net payment from $E$ to $L$ in such a renegotiation. ${ }^{13}$

For simplicity, we assume that in such renegotiations, $L$ makes a take-it-or-leave-it offer, but observe here that this assumption does not play an important role in our results. As we discuss below, for the main case we consider (when $L$ always buys information either at time 0 or time 1), the outcome is independent of the ex-post bargaining division specified here, as the time-0 agreement anticipates this division and adjusts accordingly. We further assume that renegotiation is costly, in that a fixed cost $c_{r}>0$ has to be paid by $L$, in order to renegotiate. We interpret this cost as an administrative cost, including, among others, legal expenses and the opportunity cost of time. The renegotiation cost gives the two parties an incentive to write an initial contract that minimizes the probability of renegotiating. ${ }^{14}$

After the time-0 project is undertaken, the state of the world is revealed to be either good $(G)$ or bad $(B)$ to both parties. An ex-ante contract contingent on the realization of state is assumed to be impossible. Prior to the revelation of the state, both $E$ and $I$ only know that the probability of state $G$ is $p$. The time- 1 investment is efficient in state $G$ and inefficient in state $B$. In particular, at time 2, this added investment will yield additional expected returns of $y>0$ for $E$ and 0 for $L$ in state $G$, and additional expected returns of $-y$ for $L$ and 0 for $E$ in state $B$, where $y$ is deterministic and known ex-ante by all. ${ }^{15}$

\footnotetext{
${ }^{13}$ We do not allow for contracts that give a party the decision right subject to making a payment to the other party if the action $\mathrm{A}$ is taken. Here we appeal to the standard incomplete contracting justification whereby action $\mathrm{A}$ is undescribable ex-ante, perhaps because the nature of future investment opportunities is unknown. Allowing for such a contract complicates the analysis significantly, insofar as it introduces the possibility of richer signaling. However, there is reason to believe that our qualitative results would still all hold in such a setting.

${ }^{14}$ Renegotiation costs are assumed to be paid by $L$ only because we have endowed $L$ with all the ex-post bargaining power, and it is therefore $L$ that realizes all the bilateral gain from such renegotiations. Under an alternative specification for bargaining power, it would not matter who paid these costs. The case of costless renegotiations $\left(c_{r}=0\right)$ presents some technical complications, but yields a similar equilibrium. Precise results for this case are available from the authors on request.

${ }^{15}$ The assumption that the loss of $-y$ to $L$ in state $B$ is of the same magnitude as the gain $y$ to $E$ in state $G$
} 
Table 1: Game payoffs to $(E, L)$

\begin{tabular}{||c||c|c|c||}
\hline \hline & $A$ & $N A$ & Probability \\
\hline \hline$G$ & $(R-D+x+y, D-x)$ & $(R-D, D)$ & $p$ \\
\hline$B$ & $(R-D+x, D-x-y)$ & $(R-D, D)$ & $1-p$ \\
\hline \hline
\end{tabular}

Additionally, the time- 1 investment will lead to an uncertain transfer $x$ from $L$ to $E$. This transfer $x$ can be interpreted as an expected transfer due to increased risk (i.e., asset substitution) or, alternatively, it can be interpreted as an amount of assets that $E$ can "pocket" for himself due to the added complexity of further investments. Ex ante, $E$ knows the realization of $x$, while $L$ only knows that $x$ is distributed over the interval $[a, b]$, with $0 \leq a<b$, according to the $\operatorname{cdf} F$. For simplicity we assume that $F$ is atomless with full support over $[a, b]$. Intuitively, $E$ may know more than $L$ about future risks involved with a project, or future opportunities to pocket funds. ${ }^{16}$ We refer to $x$ as $E$ 's type, and for exposition will adopt the asset-substitution interpretation of $x .^{17}$

While initially uninformed about $x, L$ can learn its realization for a cost of $c_{0}$ at time 0 prior to the signing of the initial contract, or at $\operatorname{cost} c_{1}$ at time 1 prior to the investment decision. We assume that $L$ 's decision to acquire information is observable to $E$. We also assume that $E$ cannot hold up the cost $c_{0}$ if incurred by $L .^{18}$

Finally, at time 2, all returns are realized and payoffs are made. We will assume that $R$ is sufficiently high so that $D$ (which is determined in equilibrium) is less than or equal to $R$. Table 1 summarizes the Period-2 payoffs to $E$ and $L$ conditional on the state of the world and action.

Several remarks on the payoff matrix are in order here. First, when $N A$ is chosen, the payoffs are insensitive to both the state (this feature plays no role in the analysis) and, more importantly,

simplifies the notation a little, but it has no impact on the results. This assumption, as well as others (discussed in Footnote 17), is relaxed in Appendix A.

${ }^{16}$ In principle, transfers from $E$ to $L$ may also be of concern at the contracting stage, but such cases appear far less common or natural, and we do not model them.

${ }^{17}$ We remark that this interpretation requires uncertain payments after date $2 ; x$ and $y$, therefore, should be viewed as the expectation of these payoffs given the original contract. Consequently, it would be natural for $x$ to depend on the promised payment $D$. Similarly, in many settings, the inefficiency $-y$ associated with investing in the bad state of the world would be divided between $E$ and $L$ as a function of $D$. (For example, $L$ might suffer the marginal loss of $-y$ only when $E$ was illiquid or when verifiable cash was less than $D$, with $E$ suffering the loss otherwise.) For simplicity we take the reduced-form approach of specifying $x$ and $y$ directly, the realization of $x$ to be independent of $D$, and the inefficiency $-y$ to be realized entirely by $L$, but demonstrate in Appendix A that all qualitative features of the model hold when these assumptions are relaxed.

${ }^{18}$ Otherwise, given our assumption of an ex-ante competitive lending market, $L$ will never expend these time- 0 costs, as they are sunk, and he will be held to zero profit not including these costs when the contract is signed. This assumption can be justified in a number of manners: We could assume that $E$ can commit with $L$ prior to signing a contract to reimburse these costs; or that $E$ could, at a cost $c_{0}$, make his private information verifiable; or that undertaking these costs raises $L$ 's outside option by an identical amount (perhaps because the information learned is equally valuable in alternative relationships). Alternatively, at the cost of some further analysis, we could forgo this assumption altogether by allowing $L$ to have some ex-ante bargaining power. We make this assumption simply because we want to explore the trade-off between early and late information acquisition, and our focus is not on the hold-up of ex-ante investment costs. 
the private information $x$. In the context of covenants, it is natural to interpret $N A$ as not taking a further investment; more generally, $N A$ can be interpreted as a "neutral decision" not impacted by $E$ 's private information. Second, absent renegotiation, $L$ would always prefer $N A$ to $A$, and $E$ would prefer $A$ to $N A$, while the socially optimal choice is $A$ in state $G$, and $N A$ in state $B$. This is of course the essence of our agency problem. Consequently, if $E$ has the decision right, it is efficient to renegotiate in state $B$ but not state $G$, and the converse is true if $L$ has the decision right. And third, we note that the constant $R$ plays no role in the play of the game or in our analysis, save to ensure that required payments by $E$ are feasible under the interpretation of an ex-ante wealth constrained entrepreneur. For other interpretations of our model, where $E$ and $L$ have some joint benefit to cooperation, but where $E$ is not ex-ante wealth constrained, this term is unnecessary.

\section{Equilibrium}

Before analyzing our model, we first state the outcome for the benchmark setting of symmetric information. While trivial, it will be informative to compare our results with this benchmark.

Proposition 1 If the two parties are symmetrically informed about $x$ at time 0 , then $L$ receives control rights whenever $p<\frac{1}{2}$, while $E$ receives control rights whenever $p>\frac{1}{2}$. (The two parties are indifferent between the two types of contracts when $p=\frac{1}{2}$.)

This benchmark follows immediately from observing that under symmetric information $E$ simply offers the break-even contract to $L$ that leads to the least future expected inefficiency (i.e., renegotiation costs). When $r=L$, costly renegotiation is averted in the bad state, whereas when $r=E$ renegotiation costs are instead averted in the good state. When the bad state is more likely $\left(p<\frac{1}{2}\right)$ than the good state, the expected costs are smallest when $r=L$, and vice-versa. We refer to this benchmark as the symmetric-information outcome, or the constrained-efficient outcome, since it minimizes transaction costs, subject to the constraint that contracts cannot be written on the time-1 state of the world $G$ or $B$.

Now allowing for asymmetric information, we consider Pure-Strategy Perfect Bayesian Equilibria (PSPBE). Since we are primarily interested in the interplay between costly information acquisition and the assignment of control rights, we will concentrate on parameters such that, in equilibrium, $L$ acquires information at least in some states. Specifically, we will consider parameters such that either $L$ acquires information at time 0 , or, if $L$ has chosen not to become informed at time $0, L$ will choose to become informed at time 1 in states where there is scope for renegotiation. Proposition 3 in turn will indicate that this holds provided that $c_{1}$ is small enough. Additionally, to ensure that ex-post renegotiation ensues when the inefficient action would otherwise be taken, 
Table 2: Final net payoffs after renegotiation to $(E, L)$

\begin{tabular}{||c||c|c|c||}
\hline \hline & $r=E$ & $r=L$ & Probability \\
\hline \hline$G$ & $(R-D+x+y, D-x))$ & $(R-D, D+y)$ & $p$ \\
\hline$B$ & $(R-D+x, D-x)$ & $(R-D, D)$ & $1-p$ \\
\hline \hline
\end{tabular}

we assume that $c_{1}+c_{r}<y$. That is, we assume the efficiency gains from renegotiating exceed the total cost of information acquisition and renegotiation.

We first consider play at time 1 , under this presumption that $L$ will become informed by this time if there is scope for renegotiation. We will define the "state" at this time by a pair $(r, s)$, where the first element $r \in(E, L)$ indicates who possesses the decision right, and the second element $s \in(G, B)$ indicates whether the investment state is good or bad (which is known by both parties at time 1). ${ }^{19}$ There are four states to consider. In two of the states, $(E, G)$ and $(L, B)$, there is no scope for renegotiation, as the owner of the right already prefers the optimal decision. Consequently, the net payoffs (that is, payoffs including transfers but not including information-acquisition costs) to $E$ and $L$ are $(R-D+x+y, D-x)$ for $(E, G)$, and $(R-D, D)$ for $(L, B)$. Note that if $L$ is not informed entering time 1 in one of these two states, there is no need for him to become informed at this time as such information will yield no benefit. This captures the notion that sometimes information that is acquired at time 0 is unnecessary.

If instead the state is $(L, G)$ or $(E, B)$, there will be scope for renegotiation. As noted above, we are presuming for now that at the time of this renegotiation $L$ has become informed and therefore knows $x$. In the state $(E, B)$, absent renegotiation, $E$ would choose the inefficient action $A$, since that would yield him $R-D+x>R-D$, despite a combined payoff that is less than that under action $N A$, i.e., $R-y<R$. Given this, $L$ will offer an additional payment $x$ to $E$ in exchange for action $N A$ to be taken. (Recall that $L$ has all the bargaining power, so $L$ would offer just enough to keep $E$ indifferent.) Thus, the final net payoffs are $(R-D+x, D-x)$. Similarly, for the state $(L, G)$, absent renegotiation $L$ would choose $N A$; thus $L$ will ask for $E$ 's entire marginal benefit $x+y$ in exchange for taking action $A$ instead. This yields payoffs of $(R-D, y+D)$. The final net payoffs in the four cases are summarized in Table 2. Note that Table 2 differs from Table 1 only in that in both inefficient states, renegotiation yields added benefits of $y$, which are realized entirely by $L$ since $L$ is assumed to have all of the bargaining power.

Turning to the time- 0 contract, note that in any pure strategy equilibrium there can be at most one contract associated with each choice of the decision right $r$. That is, if a contract $\{r, D\}$ is accepted in equilibrium, no type of $E$ would offer the contract $\left\{r, D^{\prime}\right\}, D^{\prime}>D$. Consequently,

\footnotetext{
${ }^{19}$ We use simple parentheses to designate states to distinguish them from contracts (which are designated with curly brackets). While we also employ parentheses to denote a pair of payoffs to the two parties, it will be clear from the context whether we are referring to states or to payoffs.
} 
there are at most two contracts offered in equilibrium, one with $r=E$ and one with $r=L$. Let $S_{E} \subseteq[a, b]$ denote the set of types who offer, in equilibrium, a contract with $r=E$; that is, $S_{E}$ gives the set of types who keep the decision right.

Now consider the case in which $L$ has not acquired information at time 0 , but will acquire information at time 1 if there is scope for renegotiation. (Later, we shall consider time- 0 information acquisition.) With ex-ante competition between lenders, $L$ must break even for any equilibrium contract. These contracts of course anticipate correctly that renegotiation will occur in states $(E, B)$ and $(L, G)$ and not in states $(E, G)$ and $(L, B)$. Given the final payoffs in Table $2, D$ is determined by the ex-ante indifference conditions for $L$. These conditions, for contracts with $r=E$ and $r=L$ respectively, are

$$
I=D-p \mathrm{E}\left[x \mid x \in S_{E}\right]-(1-p)\left(c+\mathrm{E}\left[x \mid x \in S_{E}\right]\right)
$$

and

$$
I=D+p(y-c)
$$

where $c \equiv c_{1}+c_{r}$. With $D$ satisfying these conditions, the final payoffs to $E$ for the contracts with $r=E$ and $r=L$, are in turn respectively,

$$
U_{r=E}^{E}=R-I-\mathrm{E}\left[x \mid x \in S_{E}\right]-(1-p) c+p(x+y)+(1-p) x,
$$

and

$$
U_{r=L}^{E}=R-I+p y-p c
$$

Note that $E$ 's payoff increases with $x$ when $r=E$ and is independent of $x$ when $r=L$. Consequently, if type $x$ weakly prefers $\{E, D\}$ to $\left\{L, D^{\prime}\right\}$, then all higher types $x^{\prime}>x$ would strictly prefer the former contract. And likewise, if type $x$ weakly prefers $\left\{L, D^{\prime}\right\}$ to $\{E, D\}$, then all lower types $x^{\prime}<x$ would strictly prefer $\left\{L, D^{\prime}\right\}$. It follows that in any PSPBE there will be a cut-off level $\hat{x}$ (possibly equal to $a$ or $b$ ) where all types below $\hat{x}$ pool together by offering the same contract with $r=L$, and all types above $\hat{x}$ pool on a single contract with $r=E$. Thus, the set $S_{E}$ is of the form $[\hat{x}, b] .^{20}$

To characterize this cut-off level $\hat{x}$, it will be quite useful to define the function $G(u)$ as follows:

$$
G(u) \equiv \mathrm{E}[x \mid x \geq u]-u
$$

\footnotetext{
${ }^{20}$ Strictly speaking, when interior, type $\hat{x}$ is of course indifferent, and could choose either contract. Our inclusion of this 0 -measure type in the set $r=E$ is inconsequential.
} 
Intuitively, $G(\hat{x})$ expresses the difference between the average type in the pool $[\hat{x}, b]$ of all types above $\hat{x}$, and the lowest type $\hat{x}$ in this pool.

In equilibrium, the cut-off type $\hat{x}$ must be indifferent between keeping and giving up the right. Equating expressions (3) and (4) then implies that $\hat{x}$ is given by:

$$
G(\hat{x})=(2 p-1) c .
$$

With this in hand, we now state our main result, which characterizes all PSPBEs. All proofs are in Appendix B.

Proposition 2 Assume that $L$ pays $c_{1}$ and learns $x$ at time 1 if there is scope for renegotiation. Then, a PSPBE always exists, and takes the following form:

(i) If $G(x)>(2 p-1) c$ for all $x \in[a, b]$, then all types offer $r=L$. The promised payment is $D=I-p(y-c)$.

(ii) If $G(x)<(2 p-1) c$ for all $x \in[a, b]$, then all types offer $r=E$. The promised payment is $D=I+E[x]+(1-p) c$.

(iii) If there exists $\hat{x} \in[a, b]$ such that $G(\hat{x})=(2 p-1) c$, then types $x \geq \hat{x}$ offer $r=E$, while types $x<\hat{x}$ offer $r=L$. The promised payments are: $D_{E}=I+E[x \mid x \geq \hat{x}]+(1-p) c$ when $r=E$ and $D_{L}=I-p(y-c)$ when $r=L$.

Note that since $F$ is atomless and $G$ is continuous, the condition for case (iii) will be satisfied if we are not in case (i) or case (ii), and therefore the three cases form a complete partition of the space of parameters. We discuss and interpret the equilibrium of Proposition 2 in the next section, after we first indicate sufficient conditions for its assumptions to be satisfied. Before turning to these conditions, we illustrate this Proposition with a simple example.

Example 1 Let $x$ be distributed uniformly on $[a, b]$. Then, $G(u)=\frac{b-u}{2}$. Note that $G(u)$ is monotonically decreasing in $u$. (Proposition 8 below indicates that this will hold whenever the hazard rate of $x$ is increasing.) Proposition 2 then indicates that:

(i) If $p \leq \frac{1}{2}$, then all types of $E$ give the control right to the lender $(r=L)$. (This statement holds in general, since case (i) of Proposition 2 applies.)

(ii) If $p \geq \frac{1}{2}+\frac{b-a}{4 c}$, then all types of $E$ retain the control right $(r=E)$.

(iii) If $\frac{1}{2}<p<\frac{1}{2}+\frac{b-a}{4 c}$, then $\hat{x}=b-2(2 p-1) c$. E retains the control rights if $x \geq b-2(2 p-1) c$, otherwise $L$ is granted the control right. 


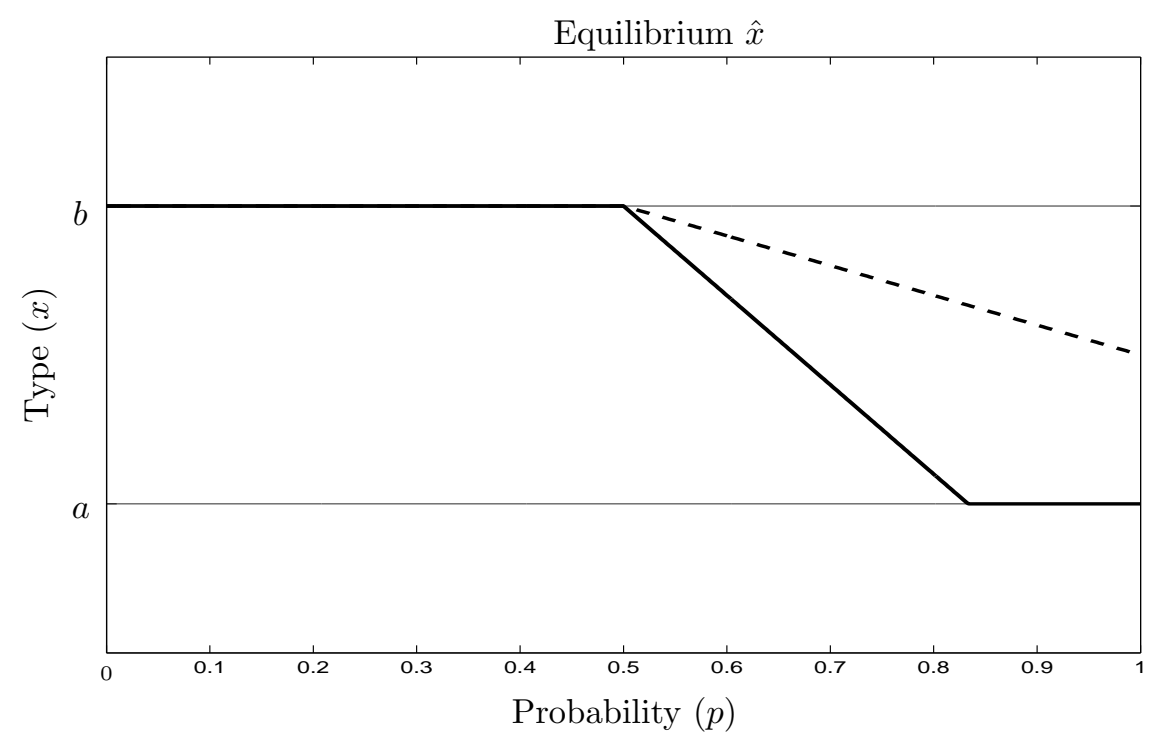

Figure 2: The figure illustrates the equilibrium cut-off level $\hat{x}$ below which $E$ gives up the control rights, for two levels of the cost $c$. The dashed line corresponds to a lower cost than the solid line.

The allocation of control rights as a function of $p$ in this example is depicted in Figure 2. The solid line and the dashed line represent two different values of costs $c$. A cut-off value of b indicates that none of the types $E$ retain control rights (control rights are always given to L), while a cut-off value of a indicates that all types $E$ retain control rights. When the cut-off level is in between, types $E$ above the cut-off retain control, while those below the cut-off give control to L.

For Proposition 2, we assumed that if $L$ is uninformed entering into time 1 , he will prefer to acquire information in states $(E, B)$ and $(L, G)$ - that is, when there is scope for renegotiation. Proposition 3 indicates that such preferences follow if $c_{1}$ is small enough. Intuitively, the proof shows that the losses to $L$ from bargaining with asymmetric information are bounded away from 0 , and, consequently, information acquisition is preferred if the cost to this is small enough.

Proposition 3 Assume that $L$ does not acquire information at time 0 . Then, there exists $\bar{c}_{1}>0$ such that, for $c_{1} \leq \bar{c}_{1}, L$ acquires information at time 1 in states $(E, B)$ and $(L, G)$.

We now turn to the case where $L$ acquires information at time 0 . As noted above, we assume that $E$ can commit to reimburse $L$ for this information-acquisition cost $c_{0}$, or alternatively, can pay it herself. Thus, information will be acquired at time 0 rather than at time 1 if the ensuing break-even contract for $L$ yields higher expected profits for $E$ (since lenders compete ex ante with one another to contract with $E$ ). Proposition 4 follows immediately.

Proposition 4 If $L$ learns $x$ at time 0 , then 
(i) if $p>\frac{1}{2}, r=E$ and $D=x+I+c_{0}+(1-p) c_{r}$, and the net profits of $E$ are $R-I+p y-$ $c_{0}-(1-p) c_{r}$

(ii) if $p<\frac{1}{2}, r=L$ and $D=-p y+I+c_{0}+p c_{r}$, and the net profits of $E$ are $R-I+p y-c_{0}-p c_{r}$.

When $L$ acquires information at time 0 , the total information cost is $c_{0}$, while the expected renegotiation cost is the smaller of $p c_{r}$ and $(1-p) c_{r}$. Since we are assuming that information will either be acquired at time 0 or at time 1 if there is scope for renegotiation, the time 1 action taken will be efficient. Given risk neutrality, it follows that the contract that maximizes E's utility subject to the lender breaking even is the contract that minimizes the sum of expected informationacquisition costs and expected renegotiation costs. Hence, the choice between acquiring information at time 0 and acquiring it at time 1 follows from simply comparing these costs, as the following proposition states.

Proposition 5 Assume that $c_{1}$ is small enough such that $L$ would acquire information at time 1 when there is scope for renegotiation if he had not already done so at time 0 . Then, $L$ acquires information at time 0 if and only if

$$
c_{0}+\min (p, 1-p) c_{r} \leq\left(c_{1}+c_{r}\right)[p F(\hat{x})+(1-p)(1-F(\hat{x})] .
$$

Early information acquisition imposes the inefficiency of paying the information cost when it might not be necessary. More precisely, late information acquisition results in an information-spending saving of $c_{0}-c_{1}(p F(\hat{x})+(1-p)(1-F(\hat{x})))$ compared with early information acquisition. This saving is always positive provided that $c_{0} \geq c_{1}$ (i.e., provided that the cost of acquiring information does not increase too significantly over time). On the other hand, early information acquisition reduces the expected renegotiation costs by minimizing the probability of renegotiating, yielding a cost saving of $c_{r}(\max [(1-2 p), 0]-(1-2 p) F(\hat{x}))$. (As we will note in the following Section, this savings is zero whenever $p \leq \frac{1}{2}$, as $p \leq \frac{1}{2}$ implies we are in case (i) of Proposition 2 where the control right is always assigned in the manner that minimizes renegotiation.) Generally, whether early information acquisition is preferred to late information acquisition depends on how the additional information cost compares to the saved renegotiation cost.

Propositions 3 and 5 jointly give conditions under which information will be acquired at time 1 if there is scope for renegotiation. The former indicates when this will be preferred to no information acquisition, while the latter indicates when this will be preferred to information acquisition at time 0 . In the following section we analyze Proposition 2 under the maintained assumption that these conditions are satisfied. 


\section{Equilibrium Properties and Discussion}

In this section we analyze the properties of our main result, Proposition 2; we derive several comparative-statics results; we examine the relative frequency of different types of renegotiation; and we further analyze the decision regarding the timing of information acquisition.

Returning to Proposition 2, the interpretation of the equilibrium condition comparing $G(x)$ and $(2 p-1) c$ is straightforward. First note that the latter term, $(2 p-1) c$, measures the additional renegotiation and information-acquisition costs that must be undertaken when $r=L$ instead of $r=E$ : this cost is given by $p c-(1-p) c=(2 p-1) c$. (The cost is negative if $p<\frac{1}{2}$, signifying lower renegotiation costs under $r=L$ than under $r=E$.)

Turning to $G(x)$, suppose that types $[u, b]$ retain the decision right. (Recall that we previously showed that in any PSPBE there must be a cut-off level such that types retain the decision right if and only if they exceed this level.) Then, $L$ would expect asset-substitution activity given by $E[x \mid x \geq u]$ when $r=E$, for which $L$ must be reimbursed ex-ante. ${ }^{21}$ The lowest type choosing $r=E$, type $u$, would only benefit from asset substitution activity in the amount $t$. The difference between these two, $\mathrm{E}[x \mid x \geq u]-u=G(u)$, measures the adverse-selection cost faced by this lowest type $u$ choosing $r=E$.

In equilibrium, all types must compare the adverse-selection cost from choosing $r=E$ with the excess renegotiation cost from choosing $r=L$. The adverse-selection cost is always greatest for the lowest type choosing $r=E$, and this is always positive. The excess renegotiation cost, in contrast, is only positive if $p \geq \frac{1}{2}$. When instead $p<\frac{1}{2}$, renegotiation costs are less for $r=L$ than $r=E$, and consequently there is no equilibrium with some types choosing $r=E$; the lowest type choosing $r=E$ would always benefit by defecting to $r=L$. Hence, when $p<\frac{1}{2}$ case (i) of Proposition 2 obtains, all types choosing $r=L$. This corresponds with the constrained efficient symmetric information outcome given in Proposition 1.

In contrast, when instead $p>\frac{1}{2}$, the allocation of the decision right diverges from the constrained efficient outcome of Proposition 1 if $(2 p-1) c$ is not too large. With $p>\frac{1}{2}$, the constrained efficient outcome involves all types $E$ retaining the decision right. However, provided that $(2 p-1) c$ does not exceed $G^{M} \equiv \max _{x} G(x)$, case (iii) obtains in Proposition 2, whereby low types will prefer to give the decision right to $L$ despite the associated inefficiency in renegotiation and information acquisition costs. Intuitively, the additional renegotiation and information-acquisition costs that must be undertaken when $r=L$ instead of $r=E$ is less for some low types than the adverse-

\footnotetext{
${ }^{21}$ This follows from noting that, absent renegotiation, $E$ would always choose $A$ if she had the right, and $L$ would always choose $N A$. Hence, in all states, $E$ requires an added transfer of $x$ if she has the right instead of $L$. This transfer alters threat points, and is maintained through our renegotiation. In contrast, any efficiency gain $y$ is captured entirely by $L$ in our renegotiation due to our endowing $L$ with the bargaining power through a take-it-or-leave-it offer.
} 

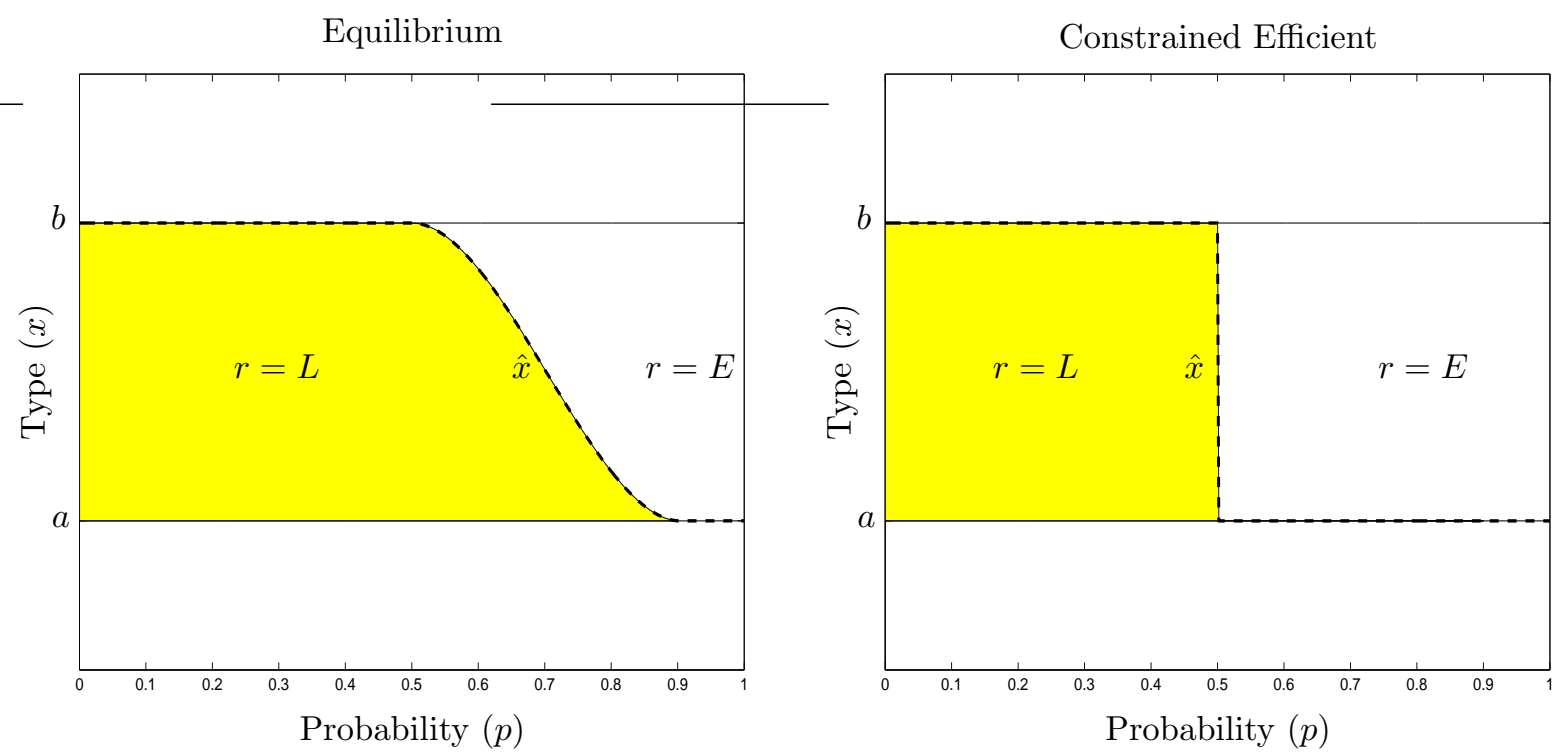

Figure 3: The figure illustrates the equilibrium allocation of the control rights for all levels of $p$ when information is asymmetric - left panel - in comparison with the symmetric information benchmark case - right panel. The shaded areas represent the types $x$ that relinquish the control rights.

selection costs they would instead incur by retaining the decision right together with all the high types who choose to do so. In equilibrium, the lowest type choosing $r=E$ is indifferent: she must face adverse-selection costs equal to the information and renegotiation-inefficiency costs of instead choosing $r=L$; that is, the cut-off type is given by $G(\hat{x})=(2 p-1) c$.

Finally, if $(2 p-1) c>G^{M}$, then the adverse-selection cost for all types choosing $r=E$ will always be less than the excess information and renegotiation costs from choosing $r=L$. In such an event, case (ii) of Proposition 2 obtains, whereby all types choose $r=E$. Note that since $G(0)>0$, $(2 p-1) c>G^{M}$ can only occur when $p>\frac{1}{2}$. When this case occurs, the allocation of the decision right again matches the constrained efficient outcome of Proposition 1.

Proposition 6 summarizes how the allocation of the control right that follows from Proposition 2 differs from the constrained efficient benchmark of Proposition 1. This comparison is depicted in Figure 3. In this figure the left panel indicates the control allocation for any value of $p$ under asymmetric information, whereas the right panel gives the benchmark symmetric information allocation. Shaded areas represents types of $\mathrm{E}$ that give up control of the decision right to $L$. Note that with asymmetric information, for any given $p$, the set of types $E$ that give up this control right under asymmetric information is a superset of the set of types $E$ that give up this right under symmetric information.

Proposition 6 Under asymmetric information, when $p>\frac{1}{2}$ and $G^{M}>(2 p-1) c$, the uninformed 
party $L$ receives the decision right more frequently than under the constrained efficient symmetric information outcome. When these conditions do not hold, the allocation of the decision right coincides with the constrained efficient symmetric information outcome.

Comparative-static properties of the equilibrium follow from the behavior of the function $G$. $G$ is weakly positive and equals 0 at $b$. Its maximum value, $G^{M}$, is at least as large as $G(0)=\mathrm{E}[x]-a$. $G$ need not, however, be monotonically decreasing, which in general makes the local dependence of $\hat{x}$ on parameters such as $p$ or $c$ ambiguous. The following two propositions, however, provide conditions that ensure this monotonicity. First, Proposition 7 indicates that a necessary and sufficient condition for $G$ to be monotonically decreasing is that the function $G$ is strictly less than the inverse hazard rate of $x$, defined as $(1-F(u)) / \frac{\partial[F(u)]}{\partial u}$. The second proposition, Proposition 8 , indicates that this condition is always satisfied if $x$ satisfies the standard increasing hazard rate assumption, which, as is well-known, is satisfied by a large class of common distributions including the normal, the truncated normal, the exponential, the truncated exponential, and the uniform distributions, among other distributions.

Proposition 7 Let $h$ denote the hazard of the distribution of $x$. Then $G(x)$ is strictly decreasing at $x$ if and only if

$$
G(x)<\frac{1}{h(x)}
$$

Proposition 8 If the hazard rate of the distribution of $x$ is increasing, then $G(x)$ is monotonically decreasing.

As Proposition 9 below indicates, uniqueness and a number of simple comparative-static properties of our equilibrium follow from the monotonicity of $G$. One of the comparative statics we are interested in is how the contract varies with the amount of asymmetric information. Since changes in asymmetric information, however, may alter the support of $x$, we need a measure of asymmetric information that is invariant to shifts in the support, unlike second-order stochastic dominance. To this end, we employ the following partial ordering for the dispersion of a distribution.

Definition 1 A distribution $F$ is said to be more dispersed than a distribution $F^{\prime}$ if $F^{-1}\left(q^{\prime}\right)-$ $F^{-1}(q) \geq F^{\prime-1}\left(q^{\prime}\right)-F^{\prime-1}(q)$ whenever $0<q \leq q^{\prime}<1 .^{22}$

\footnotetext{
${ }^{22}$ See Shaked and Shanthikumar (1994). Note that our assumptions on the distribution of $x$ imply that $F$ is continuous and strictly increasing, which makes $F^{-1}$ unambiguously defined on [0,1]. Intuitively, this definition says that a distribution with cdf $F$ is more disperse than one with cdf $F^{\prime}$ if for any range of probabilities, the domain of the random variable which maps into this range is larger for $F$ than for $F^{\prime}$. Under this definition, a random variable $X$ is less dispersed than $Y$ if and only if $Y$ has the same distribution as $X+\phi(X)$ for some increasing function $\phi$. If the logarithm of the pdf of $X$ is concave, which is the case for the uniform, (truncated) normal, (truncated) exponential, etc., distributions, and which also implies that the hazard rate of $X$ is increasing, then, for any random variable $Z$ independent of $X, X+Z$ is more dispersed than $X$. We also note that the convolution of two random variables with increasing hazard rates has an increasing hazard rate, thus ensuring that $G$ remains monotonic.
} 
With this definition in hand, we now state several comparative-static results.

Proposition 9 Let $p>\frac{1}{2}$. If $G$ is strictly decreasing over the range $[a, b]$, then:

(i) $\hat{x}$ is unique.

(ii) $\hat{x}$ decreases with both $p$ and $c=c_{1}+c_{r}$.

(iii) If $F^{\prime}$ is less disperse than $F$ (i.e., there is less asymmetric information), then $F^{\prime}\left(\hat{x}^{\prime}\right) \leq F(\hat{x})$.

This proposition indicates that the proportion of types who give away the control rights inefficiently due to asymmetric information is smaller when the renegotiation and information-acquisition cost $c$ is large, when the probability of the good state $p$ is large, and when the distribution of $x$ is less disperse. Intuition for these results is straightforward. As noted above, $G(x)$ represents the adverse-selection costs to $x$ of choosing $r=E$ if he is pooled together with all higher types $[x, b]$ in choosing $E$. If $G$ decreases monotonically, then by expanding the interval of types $[x, b]$ that choose $r=E$ by lowering the cut-off $x$, the adverse-selection cost to the lowest type $x$ in this pool increases monotonically as well. ${ }^{23}$

For any equilibrium where some types $E$ hold control rights and other types do not, the marginal type must be indifferent to holding control rights and giving them up. If the cost of choosing $r=L$ increases either by increasing $p$ (making renegotiation more likely) or by increasing $c$ (increasing the cost of renegotiation), and if $G$ decreases monotonically as well, then it follows that more types will choose $r=E$ until the adverse-selection cost for the marginal type choosing $r=E$ increases correspondingly. Consequently, the equilibrium cut-off $\hat{x}$ falls. Similarly, less dispersion in asymmetric information implies that the adverse-selection cost for the lowest type in any given pool choosing $r=E$ decreases. Consequently, more types will join this pool, and $\hat{x}$ will fall, until the cost for the marginal type once again equals the cost of inefficient renegotiation. We illustrate Proposition 9 with the following example.

Example 2 Consider again the uniform distribution of Example 1. As noted in this example, provided that $\frac{1}{2}<p<\frac{1}{2}+\frac{b-a}{4 c}$, the marginal type choosing $r=E$ is given by $\hat{x}=b-2(2 p-1) c$. (If the condition on $p$ is not met, all types choose the same contract.) Note that, as indicated in Proposition 9(ii), this cut-off $\hat{x}$ is clearly decreasing in $p$ and $c$.

Now suppose that instead $x$ is distributed uniformly over $[a-\epsilon, b+\epsilon]$, with $\epsilon>0$. Dispersion of $x$ increases in $\epsilon$. And provided that $p$ is such that an interior solution obtains, it follows that

\footnotetext{
${ }^{23}$ This condition would not, for example, hold at $x$ if there was a mass point at $x$, in violation of the increasing hazard rate assumption. In particular, lowering the cut-off by a small amount $\epsilon$ to include $x$ would lower the mean of the pool by more than $\epsilon$.
} 


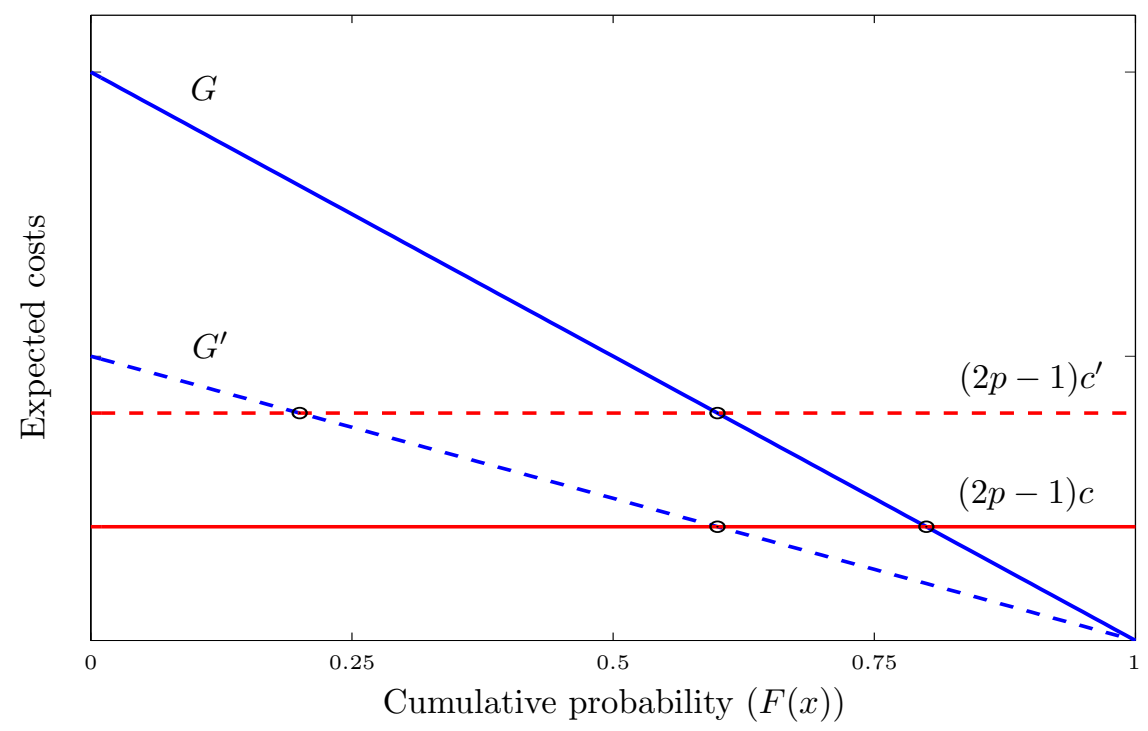

Figure 4: The figure illustrates the equilibria obtaining for two different costs, $c^{\prime}>c$, and for two uniform distributions for $x,[a, b]$ and $\left[a^{\prime}, b^{\prime}\right]$ with $b-a>b^{\prime}-a^{\prime}$.

$\hat{x}=b+\epsilon-2(2 p-1) c$, and therefore, that $F(\hat{x})=\frac{b-a+2 \epsilon-2(2 p-1) c}{b-a+2 \epsilon}$, which is increasing in $\epsilon$. Thus, more asymmetric information increases the proportion of types who choose to relinquish the right to $L$ even though this is inefficient.

Figure 4 shows the determination of the equilibrium for two different costs, $c^{\prime}>c$, and two distributions for $x$, with $F$ more dispersed than $F^{\prime}$. (It is immediate that different probabilities $p^{\prime}>p \geq \frac{1}{2}$ have the same effect as different costs.) The functions $G$ and $G^{\prime}$ correspond to the two distributions $F$ and $F^{\prime}$ respectively. On the horizontal axis we plot the cumulative probability $F(x)$ and $F^{\prime}(x)$ - since the economically meaningful comparison is not between cut-off levels $\hat{x}$, but between the probabilities $F(\hat{x})$ that there is renegotiation in the good state. (For example, shifting the distribution of $x$ by a constant changes $\hat{x}$, but does not change the amount of asymmetric information, and consequently does not alter $F(\hat{x})$ or payoffs in any state.) Adverse selection and renegotiation costs are plotted on the vertical axis. The adverse-selection cost for the lowest type choosing $r=E$, is given by $G$ and $G^{\prime}$. If Proposition 8 is satisfied, these costs decrease with the cut-off $\hat{x}$, and, therefore, with $F(\hat{x})$ as well. (They are linear here only because of the uniform distribution chosen in this example). Additional renegotiation costs from choosing $r=L$ rather than $r=E$ are depicted by the horizontal lines at $(2 p-1) c$ and $(2 p-1) c^{\prime}$ for the two different costs. The equilibrium cut-off type is given by the intersection of this adverse-selection cost and the additional renegotiation cost. The figure clearly indicates that higher costs and less dispersion in information lead to lower equilibrium values of $F(\hat{x})$, and consequently to less renegotiation.

Proposition 6 indicated that under asymmetric information $L$ obtains the decision right more 
often than under the constrained efficient outcome at time 0 , which in turn implies that $L$ renegotiates to sell the right more frequently than under the constrained efficient outcome at time 1 . Empirically, however, one is likely to only observe absolute magnitudes of renegotiation in each direction. The following proposition gives conditions under which the frequency of renegotiations where the uninformed party gives up rights exceeds that where the informed party gives up rights. ${ }^{24}$

In particular, in our equilibrium, $L$ renegotiates to sell the right with probability $p^{s}=p F(\hat{x})$ if $p>\frac{1}{2}$ and $p^{s}=p$ if $p<\frac{1}{2}$, while $L$ renegotiates to obtain further rights with probability $p^{b}=(1-p)(1-F(\hat{x}))$ if $p>\frac{1}{2}$ and $p^{b}=0$ if $p<\frac{1}{2}$. When $p<\frac{1}{2}$, all renegotiation involves transferring rights from $L$ to $E$. When instead $p>\frac{1}{2}$, the following obtains immediately.

\section{Proposition 10 Let $p>\frac{1}{2}$.}

(i) $p^{s}>p^{b}$ if and only if $p>1-F(\hat{x})$.

(ii) If $G$ is monotonic, the fraction $\frac{p^{s}}{p^{s}+p^{b}}$ of all renegotiations that involve $L$ giving up rights (as opposed to $E$ giving up rights) decreases with $c$, and decreases if $F$ becomes less disperse.

(iii) Consider a sequence of economies indexed by $n \in \mathbb{N}$ characterized by $\left(p_{n}, c_{n}, F_{n}\right)$. The fraction $\frac{p_{n}^{s}}{p_{n}^{s}+p_{n}^{b}}$ of all renegotiations that involve $L$ giving up rights tends to 1 when either a) $p_{n}$ tends to 1 and $F_{n}\left(\hat{x}_{n}\right)$ is bounded away from $0,{ }^{25}$ or b) $F_{n}\left(\hat{x}_{n}\right)$ tends to 1 - in particular, if $F$ and $p$ are fixed and $c_{n} \rightarrow 0$.

If $p \leq \frac{1}{2}$, all renegotiations involve $L$ transferring rights for considerations to $E$. If instead $p>\frac{1}{2}$, Proposition 10 indicates that the fraction of renegotiations that involve $L$ instead of $E$ giving up rights for considerations increases in asymmetric information and decreases in the costs of

\footnotetext{
${ }^{24}$ Some have suggested to us, as an alternative explanation for strict covenants, that there is an asymmetry arising in renegotiations due to the fact that it is "improper" (and at times may be illegal) for shareholders to undertake an inefficient action that transfers wealth from debtholders, and that any renegotiation whereby debtholders make some other concession to shareholders to prevent such an action would be "unseemly". This explanation does not strike us as convincing for several reasons. First, such asset substitution activity is central to shareholder-debtholder agency conflict in finance, and the possibility of such activity is well-acknowledged both in practice and in the finance literature. Second, it is not clear why such a renegotiation is any more "unseemly" than the converse renegotiation that is often observed in practice, where shareholders make some concession to debtholders in exchange for debtholders removing their veto over an efficient action. In both cases, the status-quo action that will be taken absent renegotiation is suboptimal, and for the same reason - the party with the right to make the decision prefers the suboptimal action. And third, to the extent that a distinction between the two can be made, it is by no means obvious to us that renegotiations to enhance efficiency are any more prevalent than those to avoid inefficiencies in other settings. For example, legal proceedings in a civil case typically involve costs for both parties involved, whereas a pre-trial settlement of such a case can be viewed as a negotiation designed to avoid the inefficiencies of such proceedings. Consequently, we would instead argue that there is no natural or legal distinction between these two types of renegotiations, and, rather, that assessments of which renegotiations appear "less unseemly" are likely to simply reflect which type of renegotiation is in fact observed in practice, and therefore, are no more than a restatement of the observed asymmetry.

${ }^{25}$ The condition that $F_{n}\left(\hat{x}_{n}\right)$ is bounded below away from 0 holds automatically if $F_{n}=F$ is fixed and $G$ is decreasing.
} 
renegotiation and information acquisition. Furthermore, the proposition lists conditions under which all observed renegotiation involves the lender giving up rights. This would happen, in particular, if renegotiation and information-acquisition costs were small relative to the degree of asymmetric information, which seems quite plausible.

Finally, we conclude our analysis by returning to the question of the timing of the information acquisition of $L$. Recall from Proposition 5 that information is acquired late if and only if

$$
c_{0}+\min (p, 1-p) c_{r}-\left(c_{1}+c_{r}\right)[p F(\hat{x})+(1-p)(1-F(\hat{x}))] \geq 0 .
$$

The left hand side of this inequality gives the relative benefit of late information acquisition; that is, the difference between expected information acquisition and renegotiation costs when information is acquired at time 0 instead of at time 1 . Trivially, it follows that an increase in $c_{0}$ increases the relative benefit of late information acquisition. In contrast, the effect of an increase in $c_{1}$ is ambiguous, as $\hat{x}$ is a function of $c_{1}$. The following proposition indicates, however, that the relative benefit of late information acquisition decreases with the dispersion of asymmetric information, and increases with $c_{1}$ when $c_{0}=c_{1}$.

Proposition 11 Assume that $G$ is strictly decreasing over $[a, b]$. Then, (i) an increase in the dispersion of the distribution $F$ decreases the relative benefit of late information acquisition ; and (ii) if $c_{0}=c_{1} \equiv c_{I}$, then an increase in $c_{I}$ increases the relative benefit of late information acquisition.

Part (i) captures the intuitive observation that, with a more disperse distribution, the ex-ante allocation of the control right in the case of late information acquisition is less efficient $(F(\hat{x})$ increases), and therefore the associated costs are higher. For part (ii), an equal increase in both $c_{0}$ and $c_{1}$ has two effects. First, in some states of the world, late information need not be acquired; and second, late information acquisition becomes more efficient, as $F(\hat{x})$ decreases with the information costs. Both this direct and this indirect effect serve to increase the relative benefit of late information acquisition here.

As a final note, it is worth emphasizing that, while we demonstrate in Appendix A that our results are qualitatively robust to many generalizations, these results do depend on the nature of the informational asymmetry. In particular, it is important that the informed party have superior information about the division of surplus under different actions ( $x$ in our model), rather than about the total surplus under different actions ( $y$ in our model). If parties were both informed about $x$ and instead $E$ was better informed about $y$, then $\mathrm{E}$ would be more willing to relinquish control rights for low values of $y$ than for high values of $y$. But this could lead, in equilibrium, to E maintaining excessive control, so as not to signal low values for the overall project. 


\section{Empirical Implications}

Our model has a number of testable implications for debt covenants, several of which are distinctly different from others in the literature. In this section we briefly discuss these implications. We highlight five different sets of testable predictions.

Strict Covenants and Asymmetric Renegotiation. First, as discussed in the introduction, our model implies that debt covenants will be strict (i.e., close to violation) when issued, and that the renegotiation of such debt covenants will be asymmetric, with renegotiations that typically weaken such covenants rather than tighten them. It is worth noting that these predictions do not readily follow from most other common models of debt covenants. However, unlike our other predictions below, they suffer from a lack of a clear testable benchmark. Exactly how strict should one expect covenants to be, and what renegotiation should be expected? Other models are silent on these questions, and consequently, our predictions here are not easily quantifiable.

Nonetheless, the evidence of Chava and Roberts (2005) on covenants strictness (discussed in the introduction) is rather striking. If debt covenants are simply an ex-ante unbiased estimate of the future states in which investments should and should not be undertaken, or if renegotiations are costly, one would not expect to see covenants that are so likely to be in violation so soon after the debt is issued. Our model, in contrast, obtains strict covenants as a basic prediction. Similarly, we are not aware of other models of debt covenants predicting the asymmetric renegotiation that is implied by our model and is true in practice (although a couple of models simply impose this as an initial modelling assumption).

Renegotiation Costs and Debt Covenants. A more precise comparative static derived from our model is that covenant strictness (once again, measured at the time debt is issued, as in Chava and Roberts (2005)) should decrease with renegotiation costs (Proposition 9(ii)). (And together with any implication in this section on covenant strictness is a complementary prediction on frequency of early covenant violation.) "Good" managers choose strict debt covenants in our model in order to distinguish themselves from other managers with a greater ability or propensity for asset substitution; and the level of strictness takes into account that the cost of overly strict covenants can be mitigated by renegotiation in the future when there is less informational asymmetry. This prediction contrasts with a common notion of covenants and renegotiation as alternative mechanisms for debtholder control. If that were the case, then stricter covenants would be employed when renegotiations were more costly. In contrast, in our model, strict covenants follow as a consequence of adverse selection, and the ability to renegotiate such covenants ex-post allows for stricter covenants. 
Perhaps the simplest empirical prediction regarding renegotiation costs involves the distinction between public and private debt. Free-rider problems (as well as simple coordination problems) make it very hard, if not impossible, to renegotiate dispersely held public debt outside of bankruptcy. Consequently, our model predicts that debt covenants would be stricter for private debt (which can be renegotiated) than for public debt (which is very costly to renegotiate). This point was made previously and verified empirically by Smith and Warner (1979) and Leftwich (1981).

Our model further refines and extends this hypothesis by predicting that the observed debt renegotiations will typically involve a loosening of covenants. If covenants were as likely to be tightened as loosened in renegotiations, it is not clear why covenants should be more strict when renegotiations are less costly. Indeed, when Smith and Warner (1979) and Leftwich (1981) hypothesize that the inability to renegotiate under public debt should lead to looser covenants, they seem to be implicitly assuming that renegotiations will generally only be undertaken in order to loosen covenants (which is true empirically). Our model provides a theoretical basis for this presumption and an explanation for this empirical fact together with the same prediction regarding stricter covenants for private debt.

Along similar lines, our model also predicts that other factors that increase the renegotiation cost for private debt should also lead to looser debt covenants. For example, renegotiation costs are likely to increase with the complexity of a firm's capital structure. Or, arguably, international creditors might also increase renegotiation costs. To the extent that these, or other factors, increase renegotiation costs, our model would predict that they will also be associated with looser covenants when the debt is issued.

Asymmetric Information, Complexity and Debt Covenants. Another empirical prediction of our model is that covenant strictness (measured once again at the time debt is issued) should increase with asymmetric information regarding the potential for asset substitution or other such transfers (Proposition 9(iii)). We do not know of other papers making a similar prediction; indeed, this appears to be a distinguishing prediction of an adverse selection driven model of covenants such as ours.

Asymmetric information between the issuing managers and the creditors regarding such transfers is likely to be related to "complexity" or lack of transparency within a firm. Furthermore, it is also likely to be related to the size of potential transfers, as there is likely to be more asymmetric information about transfers when the potential for transfers is large. Consequently, our model predicts that operational complexity and the lack of transparency should be positively related to the strictness of covenants when they are issued.

Several results already documented in the literature may be reinterpreted along these lines. In 
particular, we noted above in footnote 5 that Bradley and Roberts (2004) and Malitz (1986) have found that debt covenants are more likely to be present when the borrower is small, has high growth opportunities, or is highly levered, and that all three of these characteristics are plausibly related to asymmetric information. To the extent that these relationships are correct, we would further predict that all of these firm characteristics are also related with covenant tightness.

Our model also predicts that regulatory changes that lead to more corporate transparency (e.g., Sarbanes-Oxley), will lead to a weakening of covenants. And similarly, regulatory changes or legal rulings that restrict (enhance) the scope for debtholder to shareholder transfers, will lead to the future adoption of weaker (stricter) covenants.

Cash Flow and Debt Covenants. Cash flows are likely to be related to asymmetric information regarding asset substitution, and consequently, to covenant strictness in our model. In particular, the potential for intra-firm transfers is likely to be larger when there is a lot of fungible cash present, (as opposed to, say, large physical assets). That is, holding all else fixed, it is likely to be easier to secretly transfer cash than machines. More generally, a similar distinction is likely to hold for other fungible versus non-fungible assets as well. Furthermore, one might expect such transfers of cash to be easier when cash-flows are more volatile and unpredictable.

Consequently, our model would predict stricter covenants in firms and industries with high cash flow (and other fungible assets) relative to overall capital. Additionally, covenants should be stricter in firms and industries where cash-flows are volatile and uncertain, and weaker in industries where they are stable and predictable.

Asymmetric Information Regarding Investment and Covenants. Our model makes strong predictions relating the strictness of debt covenants with asymmetric information on potential transfers between the issuing managers and the creditors. Note that this implication for asymmetric information on transfers is in contrast to many other finance models, which instead focus on asymmetric information regarding the outcome of investments ( $y$ in our model). This distinction could conceivably give rise to empirical tests that would distinguish our model from other asymmetric information driven stories of covenants.

However, one difficultly in testing this distinction is that the two types of asymmetric information (regarding investments and regarding transfers) are likely to often be present together, and it may be hard to measure one independently of the other. For example, firms with risky and uncertain investments may be firms that are easy for managers to divert funds from, but complexity and the lack of transparency may also translate into risk about investments as 
well as transfers.

\section{Conclusion}

We analyze the design and renegotiation of covenants in debt contracts under asymmetric information. Specifically, we consider a setting where future firm investments are efficient in some states, but also involve a transfer from the lender(s) to shareholders. While there is symmetric information regarding investment efficiency, entrepreneur/owners are better informed about any potential transfer than the lender. The lender can learn this information, but at a cost. In this setting, we show that the simple adverse selection problem leads to the allocation of greater ex-ante decision rights to the uninformed party than would follow under symmetric (or full) information. This in turn implies that subsequent ex-post renegotiation is biased towards the uninformed party giving up these excessive rights.

While our results stand in contrast to standard incomplete contracting results that indicate that rights should be allocated to parties with important ex-ante investments (which frequently would be the informed party), it should be emphasized that our approach is consistent with a general Property Rights approach to ownership and control rights. In particular, following the Property Rights notion, we derive implications for the ex-ante allocation of control rights based on contractual incompleteness. We depart from Grossman and Hart (1986) and much of the following literature only in the specific contractual incompleteness on which we focus. In particular, rather than considering noncontractible ex-ante investments and future hold-up of such investments, we instead analyze the consequence of asymmetric information and renegotiation costs.

We have attempted to focus on one particular class of contracts for concreteness (i.e., debt contracts) while at the same time presenting the model with sufficient generality to suggest other applications. Taking this middle line runs the risk of falling short in both regards: the model may not seem tailored sufficiently to specific important features of debt contracts while at the same time its general applicability to other contracting settings may not be clear. Given this, a few words may be in order both on debt contracts and more general applications.

In Appendix A, we indicate how one can extend the model to capture several features of debt contracts not present in the text. Among these extensions, we consider payoffs to the contracting parties that more directly follow from a standard asset substitution problem, and indicates how such a setting yields results qualitatively identical to our analysis. Also, in Footnote 12 above we further outline how one could simply alter the model to account for conditional contingencies typically found in debt covenants (i.e., that debt covenants are typically binding only when certain accounting-based conditions hold). 
More generally, our model and analysis seem appropriate for a wide range of contractual settings. What is crucial to apply our model is: a) the presence of ex-ante non-contractible future actions for which decision rights can be assigned; and b) asymmetric information between the contracting parties regarding the relative consequences of such future actions on the two parties (i.e., asymmetric information regarding how the costs or benefits from such actions will be divided). While clearly not central to all contracts, these two features seem to be prominent in many cases.

For example, home-mortgage contracts and fixed-price procurement contracts seem to exhibit a similar asymmetry in renegotiations: banks often agree to relax restrictions on home mortgages ${ }^{26}$; and contractees often agree to pay contractors more to cover "unanticipated costs" or changes in design. Similarly, sports labor contracts frequently endow their team with strong rights to restrict player transfers that are routinely weakened in renegotiations. ${ }^{27}$ Also, along these lines, Lerner and Malmendier (2003) find that in strategic alliances between pharmaceutical and biotechnology companies, the former are typically given strong termination rights, which they argue is due to the propensity of some biotechnology firms to pursue private benefits (which might take the form of interesting but commercially nonviable research) rather than to maximize returns. ${ }^{28}$

Notably, in all of these cases, the party granted the initial right is the one that appears likely to be less informed. In particular, the lender (who relaxes mortgage restrictions) is likely to be less informed about the potential for default than the homeowner for a given loan; the contractee (who has the right to approve or veto any changes in initial plans) is likely to be less informed about potential cost overruns; the team is likely to be less informed than a player about the future value of the player at the time of a potential future transfer; and the pharmaceutical company is likely to be less informed than the biotechnology company about the propensity of the latter to pursue private benefits. ${ }^{29}$ Furthermore, in all of these cases, renegotiations are frequent, and typically involve the less informed party, who has been granted these strong rights, waiving or weakening

\footnotetext{
${ }^{26}$ Examples include forbearances, reinstatements, repayment plans, and loan modifications, all of which effectively involve a lender waiving a foreclosure right in exchange for a modified loan payment plan (typically with lower shortterm payments). Additionally, lenders frequently allow homeowners with loans that exceed the current home value to walk away from their home without instigating foreclosure or going after further assets.

${ }^{27}$ See, for example, Carbonell-Nicolau and Comin (2005) who study Spanish soccer contracts, and find that while over $95 \%$ of these contracts include a required inter-team transfer payment if a player changes teams, these payments are routinely negotiated down upon a transfer, to on average $45 \%$ of the contractual fee. Similar statements appear to be true for a range of strong contractual restrictions in sports labor contracts that are frequently renegotiated in practice, and that appear to be designed to protect teams against adverse selection.

${ }^{28}$ While Lerner and Malmendier interpret this as due to a moral hazard problem, where strong rights are given to induce better actions by biotechnology firms, our model explains the same result as an adverse selection problem: If the biotechnology company's propensity to pursue such private benefits is private information, the pharmaceutical firm will be granted strong rights in equilibrium.

${ }^{29}$ Note that the first two examples both typically involve an infrequent participant in the market (homeowner, contractee), and a repeat player (lender, contractor). In one case, however, the repeat player (the contractor) likely has more information, and in the other case, the infrequent participant (the homeowner) likely does. Given this difference, it is striking that in both these cases, the uninformed party seems to be granted strong initial rights, and that renegotiation typically involves the uninformed party giving up rights.
} 
these rights. 


\section{A An Explicit Model of Debt and Asset Substitution}

In this Appendix we generalize the model in several manners that correspond with a number of institutional features of debt contracts. First, we allow the transfer from L to $\mathrm{E}$ that is associated with action $A$ to depend in a general manner on the promised debt payment and the mean and variance of returns. Second, we allow the inefficiencies under $A$ in state $\mathrm{B}$ and under $N A$ in state $\mathrm{G}$ to be asymmetric, and third, we allow for noisy outcomes to projects. We show that these features can all be incorporated simply into the model without qualitatively altering results. (Recall also that in Footnote 12 we additionally outlined how one could simply alter the model to account for contractible contingencies typically found in debt covenants.)

Consider the following changes to the model. Let the total payoff from the project be $z$ if $N A$ is taken, $x=z+y_{1}+\epsilon$ if $A$ is taken and the state is $G$, and $x=z-y_{2}+\epsilon$ if $A$ is taken and the state is $B$, with $y_{1}, y_{2}>0$. The noise term $\epsilon$ is zero-mean, and is parameterized by its standard deviation $\sigma$. This standard deviation $\sigma$ is the source of asymmetric information; managers know its realization, creditors only know its distribution over its support $[a, b]$. Thus, as in the model in the text, the expected value of the firm depends on the state of the world and the action taken, about which $E$ and $L$ are symmetric informed. Also, the informational advantage of $E$ pertains to the expected division of these total returns between debtholders and shareholders, which is affected by the variance $\sigma^{2}$ in total returns through the standard asset substitution effect.

A debt contract of face value $D$ gives $E$ an expected payment $j(D, u, \sigma) \equiv \mathrm{E}\left[(X-D)^{+} \mid u, \sigma\right]$, where $X$ is the project payoff, of mean $u$ and standard deviation $\sigma$. (That is, $E$ gets paid if and only if returns exceed the promised debt payment $D$.) It follows that $j$ decreases in $D$ and increases in $u$, and we assume that $j$ also increases in $\sigma$, at least over the range of $D$ that will be relevant to the equilibrium analysis. ${ }^{30}$ Furthermore we assume that, given the equilibrium debt level, the project means $y_{1}$ and $-y_{2}$, and the smallest possible value of the standard deviation, $a, E$ always prefers taking the project, while $L$ always prefers not taking it, absent renegotiation. (That is, as before, we assume there exists an agency conflict of asset substitution with this project. These conditions are automatically satisfied for $y_{1}$ and $y_{2}$ close to zero and $a$ large enough.) Finally, as in the text, we assume that $p$ gives the probability that the state is $\mathrm{G}$, and $c \equiv c_{1}+c_{r}$ is the combined cost to time-1 information acquisition and renegotiation.

We now proceed to show that, in this setting, we obtain a result analogous to Proposition 2. In particular, we show that as in Proposition 2, in equilibrium there is a cut-off level such that all types $\mathrm{E}$ above this cut-off level choose $r=E$, whereas all types below this cut-off level choose

\footnotetext{
${ }^{30}$ This assumption follows, for instance, if we choose the family $\epsilon$ so that, when $\sigma>\sigma^{\prime}, \epsilon(\sigma)=\epsilon\left(\sigma^{\prime}\right)+\eta$, where $\eta$ is a zero-mean independent noise (this is the case for the normal distribution). Similarly, this assumption is also satisfies if $\epsilon(\sigma)$ is a two-point distribution - if $D$ is not too high, then $h$ is strictly increasing in $\sigma$.
} 
$r=L$. Furthermore, the characterization of this cut-off takes a form similar to that in equation (6) in the text. That is, as before, when $p \leq \frac{1}{2}$ (and therefore $r=L$ is constrained efficient), the cut-off level will be above the highest type; all types will choose $r=L$. If instead $p>\frac{1}{2}$, and therefore $r=E$ is constrained efficient, there will be an interior cut-off level, unless $p$ is too close to 1 and $c$ is high. Hence, once again, $\mathrm{L}$ will be given strong decision rights as a consequence of being worse informed. Additionally, the comparisons to the constrained efficient outcome and comparative-statics results of Propositions 6, 9, 10, and 11 will all hold as before, with a suitable modification to the function $G(x)$ that measures adverse selection.

Our derivation follows along similar lines with the text. First we apply the zero-profit condition for $\mathrm{L}$ to find the equilibrium debt level for a contract with $r=E$ and for $r=L$, analogous to equations (1) and (2) in the text. This yields for $r=E$ and $r=L$ respectively,

$$
I=\mathrm{E}\left[p\left(z+y_{1}-j\left(D^{E}, z+y_{1}, \sigma\right)\right)+(1-p)\left(z-j\left(D^{E}, z-y_{2}, \sigma\right)-c\right) \mid \sigma \in S_{E}\right]
$$

and

$$
I=D^{L}-p c+p y_{1}
$$

Consequently, the expected payoffs to $E$ when $r=E$ and $r=L$ respectively, are given by,

$$
U_{r=E}^{E}=p j\left(D^{E}, z+y_{1}, \sigma\right)+(1-p) j\left(D^{E}, z-y_{2}, \sigma\right),
$$

and

$$
U_{r=L}^{E}=z+p y_{1}-p c-I
$$

where $D^{E}$ satisfies (A.1).

Now define $g\left(D, u_{1}, u_{2}, \sigma\right)=p j\left(D, u_{1}, \sigma\right)+(1-p) j\left(D, u_{2}, \sigma\right) ; g\left(D, u_{1}, u_{2}, \sigma\right)$ gives the expected payoff to $E$ taking renegotiation into account when $r=E$, debt is given by $D$, and when action $\mathrm{A}$ leads to a mean and standard deviation of $X$ of $\left(u_{1}, \sigma\right)$ in state $\mathrm{G}$ and $\left(u_{2}, \sigma\right)$ in state B. Also note, as in the text, that the set $S_{E}$ will take the form $[\hat{\sigma}, b]$, since the payoff to $E$ when $r=E$ in (A.3) is increasing in $\sigma$, and the payoff to $E$ when $r=L$ in (A.4) does not depend on $\sigma$. As before, we find the cut-off type $\hat{\sigma}$ by equating the expected returns to the lowest type $E$ that chooses $r=E$ with those of the highest type $E$ that chooses $r=L$.

Using the definition of $g$, equation (A.1) implies that,

$$
\mathrm{E}\left[g\left(D^{E}, z+y_{1}, z-y_{2}, \sigma\right) \mid \sigma \geq \hat{\sigma}\right]=-I+z+p y_{1}-(1-p) c
$$


and consequently, from equation (A.4), it follows that

$$
U_{r=L}^{E}=\mathrm{E}\left[g\left(D^{E}, z+y_{1}, z-y_{2}, \sigma\right) \mid \sigma \geq \hat{\sigma}\right]-(2 p-1) c .
$$

The equilibrium cut-off value of $\hat{\sigma}$ then follows from equating this expression with

$$
U_{r=E}^{E}=g\left(D^{E}, z+y_{1}, z-y_{2}, \sigma\right),
$$

the payoff to E when $r=E$, and solving for $\hat{\sigma}$. Analogous to the definition of $G$ in the text, define $\mathcal{G}\left(D, u_{1}, u_{2}, \sigma\right)$ by,

$$
\mathcal{G}\left(D, u_{1}, u_{2}, \sigma\right) \equiv \mathrm{E}\left[g\left(D, u_{1}, u_{2}, \sigma\right) \mid \sigma \geq \hat{\sigma}\right]-g\left(D, u_{1}, u_{2}, \hat{\sigma}\right)
$$

It then follows that in parallel with equation (6) in the text, $\hat{\sigma}$ is determined by the solution to

$$
\mathcal{G}\left(D^{E}, z+y_{1}, z-y_{2}, \sigma\right)=(2 p-1) c
$$

And now, just as with equation (6), it follows from equation (A.8) that when $p \leq \frac{1}{2}, L$ once again gets control all the time, while when $p>\frac{1}{2}$, there may be an interior solution $\hat{\sigma}$ (since $j$ increases in $\sigma$ in the needed range, and therefore so does $g$ ). Indeed, all results from Proposition 2 for $\hat{x}$ now follow immediately for $\hat{\sigma}$ in this modified model, with $G(x)$ replaced by $\mathcal{G}\left(D, z+y_{1}, z-y_{2}, \sigma\right)$. And from this result, comparative-statics for $\hat{\sigma}$ and comparisons with the constrained efficient outcome are analogous to those in Propositions 6, 9, 10, and 11 in the text.

To see how this general solution corresponds with the simpler solution in the text, first recall from the text that the relevant measure of adverse selection for the equilibrium is the average expected payment to managers across a pool of types $[x, b]$ versus the expected payment to the lowest type in this pool $x$, when $r=E$, after taking renegotiations into account. In the simple model in the text, the expected payment that $E$ receives when $r=E$ and debt is given by $D$, after taking renegotiation into account, is simply

$$
p(R-D+x+y)+(1-p)(R-D+x)=R-D+x+p y .
$$

This corresponds with $g\left(D, u_{1}, u_{2}, \sigma\right)$ in this more general model, where the manager's asymmetric information is given by $\sigma$ rather than by $x$. Thus adverse selection faced by a cut-off type $\hat{x}$ (or $\hat{\sigma}$ for the more general model here in the appendix) follows from taking expectations of these expressions over the pool $[\hat{x}, b]$ (correspondingly $[\hat{\sigma}, b]$ ), and subtracting the value of this expression for this cut-off type. For the simple model in the text, since only $x$ in the expression $R-D+x+p y$ is 
subject to asymmetric information, this measure in turn is simply given by $\mathrm{E}[x \mid x \geq t]-t$; that is, by $G(x)$. In the more general model of this appendix, asymmetric information $\sigma$ affects the manager's payoff when $r=E$ through the expression $g\left(D, u_{1}, u_{2}, \sigma\right)$. Consequently it follows that the corresponding measure of adverse-selection costs takes the more general form given by $\mathcal{G}(\sigma)$ in equation (A.7). And with this generalization, the same comparative-statics results then follow.

To explicitly determine the cut-off type $\hat{\sigma}$, one would have to first solve for $D^{E}$ and then solve equation (A.8) above. As one particularly simple example, let $\epsilon$ takes values in $\{-\sigma, \sigma\}$, with probability $\frac{1}{2}$ for each outcome. It is easily seen that there exists an open set of parameters for which default happens if and only if $\epsilon=-\sigma$, implying that $h(D, u, \sigma)=(u+\sigma-D) / 2$ for $u \in\left\{z-y_{2}, z+y_{1}\right\} .{ }^{31}$ It then follows that equation (A.8) becomes

$$
\mathrm{E}[\sigma \mid \sigma \geq \hat{\sigma}]-\hat{\sigma}-2(2 p-1) c=0
$$

which, notably, is identical to equation (6) in the text, save for $\mathcal{G}$ replacing $G, \sigma$ replacing $x$, and the constant $2 c$ replacing $c$.

\footnotetext{
${ }^{31}$ The necessary and sufficient conditions are $2(z-I)+p\left(y_{1}-y_{2}\right) \geq 0$ and $2(z-I)+p\left(y_{1}-y_{2}\right)+y_{1}+y_{2} \leq 2 a$, together with $z-y_{2} \geq b$. It is clear that they can be satisfied simultaneously.
} 


\section{B Proofs}

\section{Proof of Proposition 2:}

From the comparison of (3) and (4) it follows that, if $L$ expects types $x \geq \hat{x}$ to choose $r=E$, then an agent of type $x$ chooses $r=E$ if and only if

$$
x-\hat{x}-G(\hat{x}) \geq-(2 p-1) c .
$$

Suppose now that $G(\hat{x})>(2 p-1) c$ for all $\hat{x} \in[a, b]$. Then $\hat{x}=b$ is an equilibrium, since inequality (B.1) is never satisfied. If, on the other hand, $G(\hat{x})<(2 p-1) c$ for all $\hat{x} \in[a, b]$, then inequality (B.1) is satisfied for all $x$ when $\hat{x}$ is set to be $\hat{x}=a$. Thus $r=E$ for all types is an equilibrium.

Finally, for any $\hat{x}$ for which $G(\hat{x})=(2 p-1) c$, inequality (B.1) reduces to $x \geq \hat{x}$, which means that types $x \geq \hat{x}$ choose $r=E$ and types $x<\hat{x}$ choose $r=L$, which is consistent with the expectations of $L$.

The calculation of the contractual transfer follows immediately from equations (1) and (2).

\section{Proof of Proposition 3:}

Let $H_{L}(\hat{x})$ be the gain to $L$ from renegotiating the contract $r=L$ in state $G$ with asymmetric information, given that the equilibrium cut-off point is $\hat{x}$. Analogously, define $H_{E}(\hat{x})$ to be the gain to $L$ from renegotiating when $r=E$. We will show below that $H_{L}(\hat{x})$ and $H_{E}(\hat{x})$ are continuous functions, that $H_{L}(\hat{x})<y$ for all $\hat{x} \in(a, b]$, and that $H_{E}(\hat{x})<y$ for all $\hat{x} \in[a, b)$. It follows then that both $H_{L}$ and $H_{E}$ are bounded uniformly away from $y$ when $\hat{x}$ is confined to an interval $\left[\hat{x}_{1}, \hat{x}_{2}\right] \subset(a, b)$.

With full information, $L$ extracts all the surplus from renegotiation, $y$, whence, for any $\hat{x} \in$ $\left[\hat{x}_{1}, \hat{x}_{2}\right], L$ makes a net gain from acquiring information that is bounded below away from zero. That is, letting

$$
g\left(\hat{x}_{1}, \hat{x}_{2}\right)=y-\max \left(\sup _{\hat{x} \in\left[\hat{x}_{1}, \hat{x}_{2}\right]} H_{L}(\hat{x}), \sup _{\hat{x} \in\left[\hat{x}_{1}, \hat{x}_{2}\right]} H_{E}(\hat{x})\right),
$$

it holds that $g\left(\hat{x}_{1}, \hat{x}_{2}\right)>0$.

Consider now the equilibrium, given by $\hat{x}$, that obtains with $c_{1}=0$. If $\hat{x} \in(a, b)$ then, by continuity, there exist $\hat{x}_{1}$ and $\hat{x}_{2}$ with $a<\hat{x}_{1}<\hat{x}_{2}<b$ such that an equilibrium for $c_{1}$ small enough is given by $\hat{x} \in\left[\hat{x}_{1}, \hat{x}_{2}\right]$. Consequently, if $c_{1}$ is small enough - in particular, $c_{1} \leq g\left(\hat{x}_{1}, \hat{x}_{2}\right)$ - then $c_{1}$ is worth paying for information. If $\hat{x}=a$ when $c_{1}=0$, then $\hat{x}=a$ for positive $c_{1}$, too, and the only condition required is that $c_{1}<y-H_{E}(a)$. Analogously, if $0=G(b) \geq(2 p-1) c_{r}$, then the 
only condition required is that $c_{1}<y-H_{L}(b)$.

Finally, let us show that, when bargaining takes the form of a TIOLI offer made by $L, H_{L}$ and $H_{E}$ are strictly smaller than $y$ on $(a, b]$, respectively on $[a, b)$, and continuous. For that, we have to identify first the conditions defining $L$ 's offer.

Consider first the case $(L, G) . L$ asks a further payment $u$ from $E$ in exchange for the right to take the action. Since $E$ accepts the offer if and only if $u \leq x+y$, the expected gain to $L$ is $H_{L}(\hat{x})=\max _{u} h_{L}(u, \hat{x})$, with

$$
h_{L}(u, \hat{x})=\mathrm{E}\left[(u-x) 1_{(u \leq x+y)} \mid x<\hat{x}\right] .
$$

It is easy to see that $h_{L}(u, \hat{x})$ is strictly less than $y$ for every $u \in[a, y+\hat{x}]$, and is weakly negative for $u$ outside $[a, y+\hat{x}]$. It is also easy to see that $h_{L}(u, \hat{x})$ is continuous in $u$ and $\hat{x}$, whence its maximal value, $H_{L}(\hat{x})$, is strictly smaller than $y$ and continuous in $\hat{x}$.

In the other case, $(E, B), L$ offers a payment $v$ to $E$ in exchange for the control right, and $E$ accepts if and only if $v \geq x$. Then, $H_{E}(\hat{x})=\max _{v} h_{E}(v, \hat{x})$, with

$$
h_{E}(v, \hat{x})=\mathrm{E}\left[-(x+y) 1_{(v<x)}-v 1_{(v \geq x)} \mid x>\hat{x}\right]+\mathrm{E}[x+y \mid x>\hat{x}] .
$$

The rest of argument is analogous to that for $H_{L}$.

\section{Proof of Proposition 4:}

With perfect information on both sides, the contract will be chosen so as to minimize the renegotiation costs. These equal $p c_{r}$ if $r=L$ and $(1-p) c_{r}$ if $r=E$, whence the result.

\section{Proof of Proposition 5:}

The left-hand side of inequality (7) equals the total cost associated with early information acquisition and efficient renegotiation, while the right-hand side the total cost associated with late information acquisition, since the probability of renegotiating is $p F(\hat{x})+(1-p)(1-F(\hat{x}))$.

\section{Proof of Proposition 7:}


With $w^{+}=\max (w, 0)$ for any real $w$, direct calculation yields

$$
\begin{aligned}
G^{\prime}(z) & =\frac{d}{d z} \frac{\mathrm{E}\left[(x-z)^{+}\right]}{1-F(z)} \\
& =\frac{-(1-F(z))}{1-F(z)}+\frac{f(z) \mathrm{E}\left[(x-z)^{+}\right]}{(1-F(z))^{2}} \\
& =-1+h(z) G(z),
\end{aligned}
$$

which implies the result.

\section{Proof of Proposition 8:}

The result follows directly from Theorem 1.A.13. in Shaked and Shanthikumar (1994). For completeness, we provide a proof here.

Let $t<t^{\prime}$ and $F_{u}(w)=\frac{F(w+u)-F(u)}{1-F(u)}$ for $u \in\left\{t, t^{\prime}\right\} ; F_{u}$ is the cumulative distribution function of $x-u$ conditionally on $x \geq u$, and $G(u)$ is the mean of $F_{u}$.

The fact that $x$ has an increasing hazard rate is equivalent to $\log (1-F(w))$ being concave, where $F$ is its cdf. Since, for any concave function $\xi: \mathbb{R} \rightarrow \mathbb{R}, \xi(x+a)-\xi(x)$ decreases in $x$ for any positive $a$,

$$
\frac{1-F(w+u)}{1-F(u)}=1-F_{u}(w)
$$

decreases in $u$. In other words, the distribution $F_{t}$ dominates the distribution $F_{t^{\prime}}$ in the sense of first-order stochastic dominance (FOSD), whence it has a higher mean. Therefore, $G\left(t^{\prime}\right)<G(t)$, proving the result.

\section{Proof of Proposition 9:}

Parts (i) and (ii) follow immediately from the monotonicity of $G$. Let us prove part (iii). We'll show that, for any $t, t^{\prime}, F(t)=F^{\prime}\left(t^{\prime}\right)$ implies $G(t) \geq G^{\prime}\left(t^{\prime}\right)$, whence, by monotonicity of $G$ and $G^{\prime}$, $G(\hat{x})=G^{\prime}\left(\hat{x}^{\prime}\right)$ implies that $F(\hat{x}) \geq F^{\prime}\left(\hat{x}^{\prime}\right)$. To that end, we note that

$$
G(t)=\frac{\int_{t}^{\infty}(1-F(x)) d x}{1-F(t)}
$$

If $F(t)=F^{\prime}\left(t^{\prime}\right)=r$, then

$$
\begin{aligned}
\int_{t}^{\infty}(1-F(x)) d x-\int_{t^{\prime}}^{\infty}\left(1-F^{\prime}(x)\right) d x & =\int_{r}^{1}(1-p) d\left(F^{-1}(p)-F^{\prime-1}(p)\right) \\
& \geq 0
\end{aligned}
$$

where the last inequality is due to the fact that $F$ being more dispersed than $F^{\prime}$ is equivalent with 
$F^{-1}(p)-F^{\prime-1}(p)$ being increasing in $p$ (see Shaked and Shanthikumar (1994)). Thus $G(t) \geq G^{\prime}\left(t^{\prime}\right)$, whence $F(\hat{x}) \geq F^{\prime}\left(\hat{x}^{\prime}\right)$.

\section{Proof of Proposition 11:}

For part (i), note that the derivative of (8) with respect to $c_{I}$ gives

$$
p-(2 p-1) F(\hat{x})-\left(c_{I}+c_{r}\right)(2 p-1) \frac{\partial F(\hat{x})}{\partial c_{I}} \geq 0
$$

since $p \geq(2 p-1) F(\hat{x})$ and $\frac{\partial F(\hat{x})}{\partial c_{I}} \leq 0$. Part (ii) follows from the fact that a more dispersed $F$ translates into a higher $F(\hat{x})$. 


\section{References}

Aghion, P. and P. Bolton (1992). An 'Incomplete Contracts' Approach to Financial Contracting. Review of Economic Studies 59, 473-494.

Beneish, M. D. and E. Press (1993). Cost of Technical Violation of Accounting-Based Debt Covenants. Accounting Review 68(2), 233-257.

Beneish, M. D. and E. Press (1995). The Resolution of Technical Default. Accounting Review 70(2), 337-353.

Berglöf, E. and E.-L. Von Thadden (1994). Short-Term Versus Long-Term Interests: Capital Structure with Multiple Investors. Quarterly Journal of Economics 109, 1055-1084.

Bradley, M. and M. R. Roberts (2004). The Structure and Pricing of Corporate Debt Covenants. Duke University Working Paper.

Carbonell-Nicolau, O. and D. Comin (2005). Testing Out Contractual Incompleteness: Evidence from Soccer. NYU Working Paper.

Chava, S. and M. R. Roberts (2005). Is Financial Contracting Costly? An Empirical Analysis of Debt Covenants and Corporate Investment. Working Paper, University of Pennsylvania.

Coase, R. H. (1960). The Problem of Social Cost. Journal of Law and Economics 3, 1-44.

Dessein, W. (2005). Information and Control in Ventures and Alliances. Journal of Finance, forthcoming.

Dewatripont, M. and J. Tirole (1994). A Theory of Debt and Equity: Diversity of Securities and Manager-Shareholder Congruence. Quarterly Journal of Economics 109, 1027-54.

Gale, D. and M. Hellwig (1985). Incentive-Compatible Debt Contracts: The One-Period Problem. Review of Economic Studies 52, 647-663.

Grossman, S. J. and O. D. Hart (1986). The Costs and Benefits of Ownership: A Theory of Vertical and Lateral Integration. Journal of Political Economy 94(4).

Grout, P. A. (1984). Investment and Wages in the Absence of Binding Contracts: A Nash Bargining Approach. Econometrica $\mathbf{5 2 .}$

Harris, M. and A. Raviv (2005). Allocation of Decision-Making Authority. Review of Finance 9, $353-83$.

Hart, O. D. (1995). Firms, Contracts, and Financial Structure. Oxford and New York: Oxford University Press, Clarendon Press.

Hart, O. D. and J. Moore (1990). Property Rights and the Nature of the Firm. Journal of Political Economy 98(6). 
Harvey, C. T., K. V. Lins, and A. H. Roper (2004). The Effect of Capital Structure When Expected Agency Costs Are Extreme. Journal of Financial Economics 74, 3-30.

Hermalin, B. (1988). Adverse selection, Contract Length, and the Provision of On-the-Job Training. Ph. D. thesis, MIT Department of Economics.

Huberman, G. and C. M. Kahn (1988). Limited Contract Enforcement and Strategic Renegotiation. American Economic Review 78(3), 471-484.

Jensen, M. C. and W. H. Meckling (1976). Theory of the Firm: Managerial Behavior, Agency Costs and Ownership Structure. Journal of Financial Economics 3, 305-360.

Kirilenko, A. (2001). Valuation and Control in Venture Finance. Journal of Finance 56, 565-587.

Klein, B., R. G. Crawford, and A. A. Alchian (1978). Vertical Integration, Appropriable Rents, and the Competitive Contracting Process. Journal of Law and Economics 21(2), 297-326.

Leftwich, R. (1981). Evidence of the Impact of Mandatory Changes in Accounting Principles in Corporate Loan Agreements. Journal of Accounting and Economics 3(1), 3-36.

Lerner, J. and U. Malmendier (2003). Contractibility and Contract Design in Strategic Alliances. Stanford University Working Paper.

Malitz, I. (1986). On Financial Contracting: The Determinants of Bond Covenants. Financial Management, 18-25.

Shaked, M. and J. G. Shanthikumar (1994). Stochastic Orders and Their Applications. San Diego, CA: Academic Press.

Smith, C. and J. B. Warner (1979). On Financial Contracting: An Analysis of Bond Covenants. Journal of Financial Economics 7, 117-161.

Smith, C. W. (1993). A Perspective on Accounting-Based Debt Covenant Violations. Accounting Review 68(2), 289-303.

Spier, K. (1992). Incomplete Contracts and Signalling. Rand Journal of Economics 23(3), 432443.

Sridhar, S. S. and R. P. Magee (1997). Financial Contracts, Opportunism, and Disclosure Mangement. Review of Accounting Studies 1, 225-258.

Stole, L. and J. Zwiebel (2005). Mergers, Employee Hold-Up and the Scope of the Firm: An Intrafirm Bargaining Approach to Mergers. Stanford University Working Paper.

Sweeney, A. P. (1994). Debt Covenant Violations and Managers' Accounting Responses. Journal of Accounting and Economics 17, 281-308.

Townsend, R. (1979). Optimal Contracts and Competitive Markets With Costly State Verification. Journal of Economic Theory 21, 265-293. 
Williamson, O. E. (1985). The Economic Institutions of Capitalism. New York, NY: Free Press.

Zender, J. F. (1991). Optimal Financial Instruments. Journal of Finance 4, 201-219. 